\title{
Analytical Treatment of the Power Transfer Relationships for a Coupled, Current-Fed, Multi-Port Dual Active Bridge Converter
}

by

\section{Zachary T. Smith}

Bachelor of Science in Electrical Engineering, University of Pittsburgh, 2014

\author{
Submitted to the Graduate Faculty of \\ Swanson School of Engineering in partial fulfillment \\ of the requirements for the degree of \\ Master of Science in Electrical Engineering
}

University of Pittsburgh 


\section{UNIVERSITY OF PITTSBURGH}

SWANSON SCHOOL OF ENGINEERING

This thesis was presented

by

\section{Zachary T. Smith}

It was defended on

August 19, 2019

and approved by

Brandon Grainger, PhD., Assistant Professor, Department of Electrical and Computer

Engineering

Alexis Kwasinski, PhD., Associate Professor, Department of Electrical and Computer

Engineering

Gregory Reed, PhD., Professor, Department of Electrical and Computer Engineering

Thesis Advisor: Brandon M. Grainger, PhD., Assistant Professor, Department of Electrical and Computer Engineering 
Copyright (C) by Zachary T. Smith

2019 


\title{
Analytical Treatment of the Power Transfer Relationships for a Coupled, Current-Fed, Multi-Port Dual Active Bridge Converter
}

\author{
Zachary T. Smith, M.S. \\ University of Pittsburgh, 2019
}

Existing research has demonstrated that mutual inductors within the load ports of a Dual Active Bridge (DAB)-based converter enable fault tolerant operation. Similar research efforts with the DAB converter have also proven that incorporating a multi-winding transformer in the design can result in an interconnection of multiple DC buses with isolation and reduced switching losses. Therefore, a current-fed, multi-port DAB converter is proposed with the intention of capturing the benefits of both features. The performance of the proposed converter is evaluated against the traditional multi-port DAB. In particular, the potentially non-ideal square waveforms at load port voltages are mathematically described. The converter characteristic equations are then verified with PLECS simulations. Finally, the effects of inductor size on port voltages and power transfer are explored. The results of the analyses provide the conditions in which simplification to power flow equations for voltage-fed multi-port converters is applicable. 


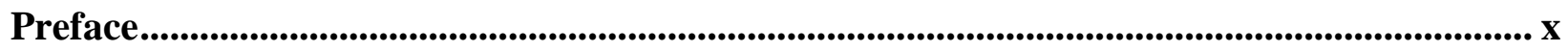

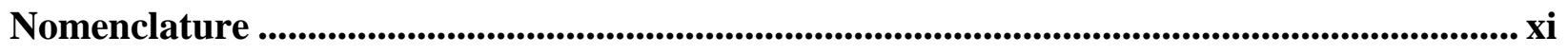

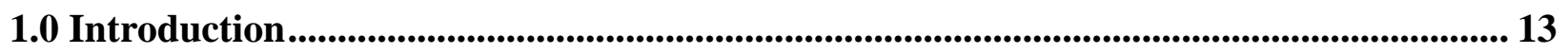

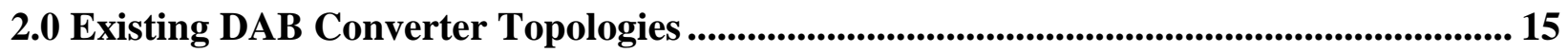

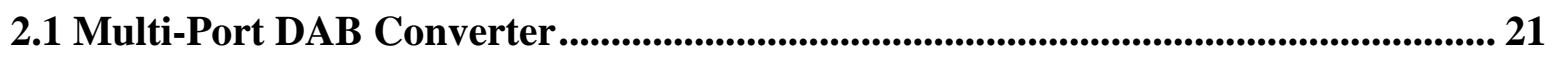

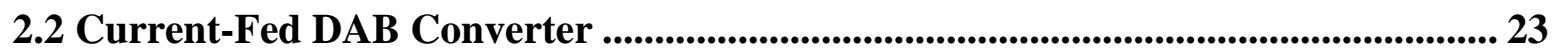

3.0 Multi-Port, Current-Fed DAB Converter Analysis ................................................. 27

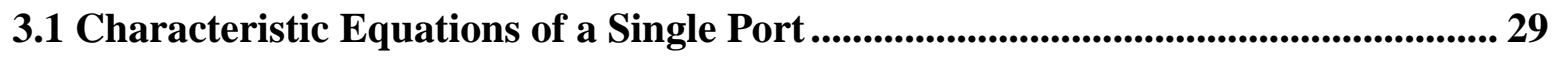

3.2 Analysis of the 3-Port Converter ........................................................................................... 37

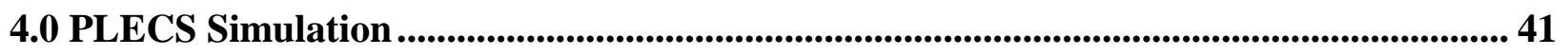

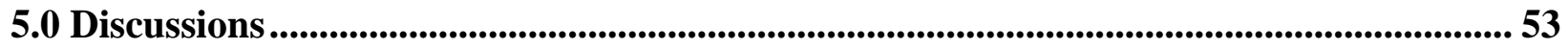

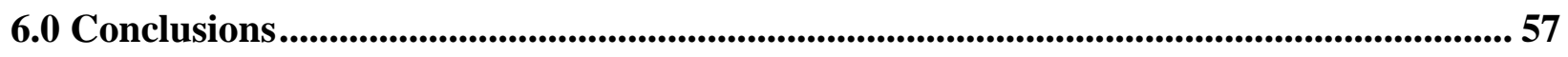

Appendix A Verification of Equations Under Various Circuit Parameters ........................... 58

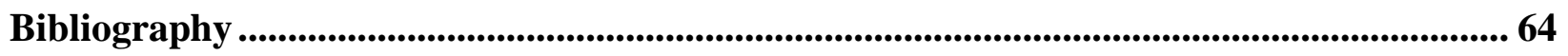




\section{List of Tables}

Table 1: Circuit Parameters 


\section{List of Figures}

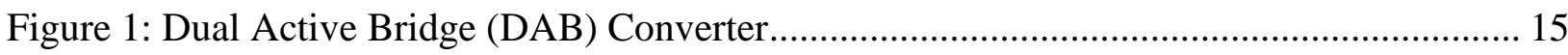

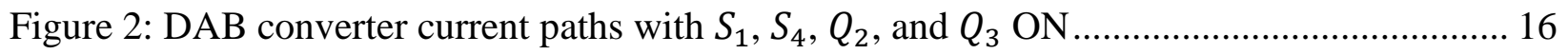

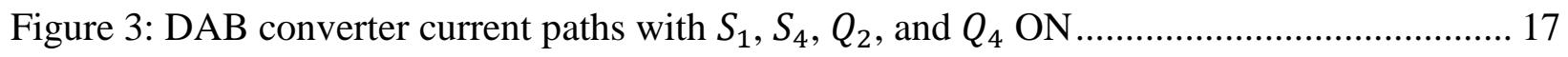

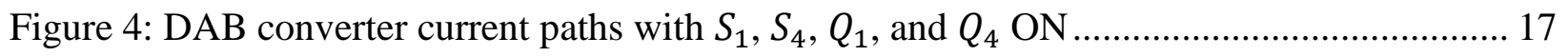

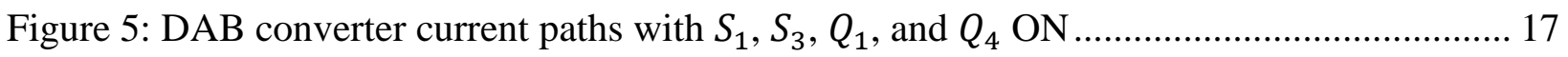

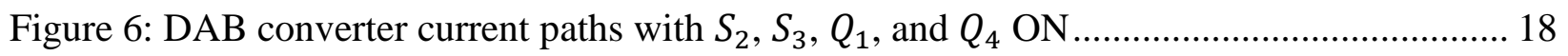

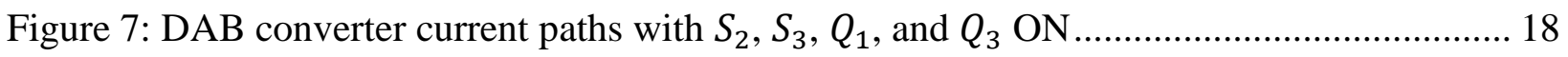

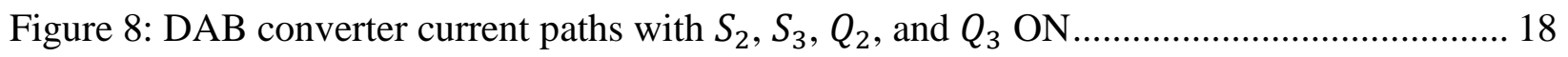

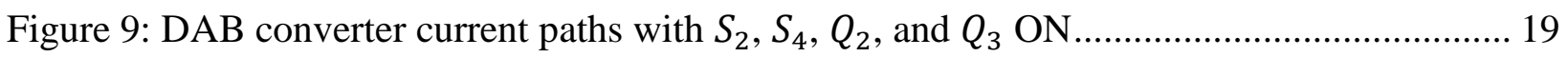

Figure 10: Single-phase-shift (a), extended-phase-shift (b), dual-phase-shift (c), and triple-phase-

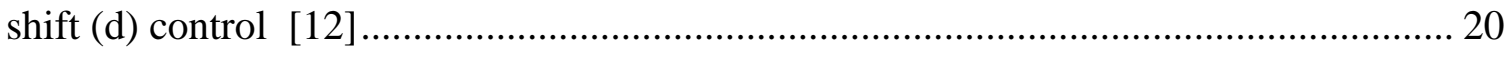

Figure 11: (a) TAB circuit topology, (b) $\Delta$-equivalent model, and (c) port voltage waveforms [13]

Figure 12: Current-fed Dual Active Bridge converter designs: (a) Inductance added before switching and (b) inductance added after switching [14] ............................................ 24

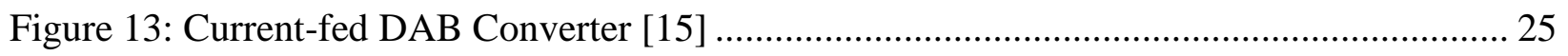

Figure 14: Operational waveforms of current-fed DAB [15] ..................................................... 26

Figure 15: Current-fed, multi-port dual active bridge topology ……………………................ 28

Figure 16: Switching voltage waveforms for each port.......................................................... 29

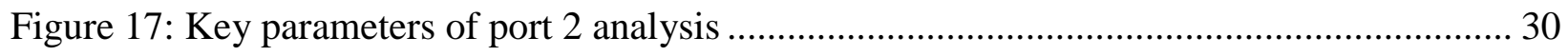


Figure 18: Switching waveforms for upper arms $v_{\text {arm } 2-1}$ and $v_{\text {arm } 2-2}$ and the difference

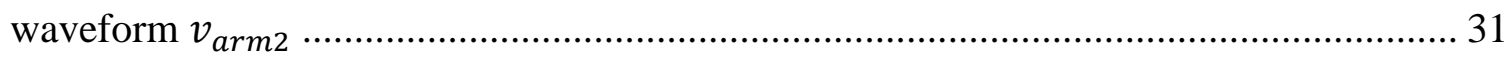

Figure 19: Port 2 analysis - mutual inductor parameters ................................................ 33

Figure 20: Port 2 anaylsis - nodal analysis of mutual inductor pairs ...................................... 34

Figure 21: Port 2 analysis - port voltage $v_{2}$ in terms of controllable parameters $v_{T 2}$ and $v_{\text {arm } 2} 36$

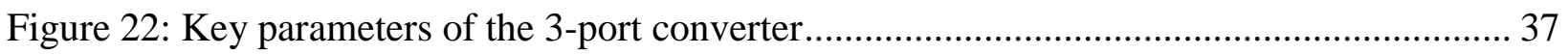

Figure 23: PLECS circuit model of current-fed three-port DAB converter ............................ 42

Figure 24: Current-fed switching submodule Sub2 and Sub3 ............................................ 43

Figure 25: Mutual inductor submodule Ldc and Ldc1 ................................................. 43

Figure 26: Arm switching submodule Sub2 through Sub5 ............................................... 44

Figure 27: Individual arm voltages for each current-fed port and each port's voltage difference

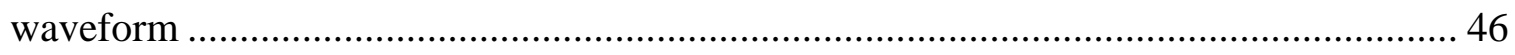

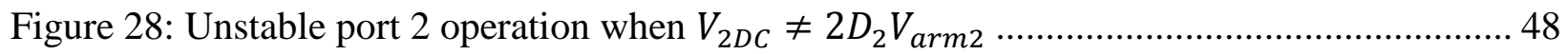

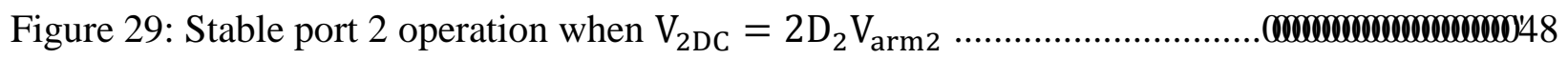

Figure 30: Analytical vs PLECS simulation waveforms for port voltages and switching waveforms

Figure 31: Analytical vs PLECS simulation waveforms for power flow at each port ............... 51

Figure 32: Current-fed port voltage waveforms $v_{2}$ and $v_{3}$ with inductance ratios $\left(L_{d c}-L_{M}\right) / L_{x}$ between $1 \%$ and $200 \%$ (results taken from PLECS simulation) .................................. 54

Figure 33: Power transfer at current-fed ports with respect to the inductance ratios $\left(L_{d c}-L_{M}\right) / L_{x}$

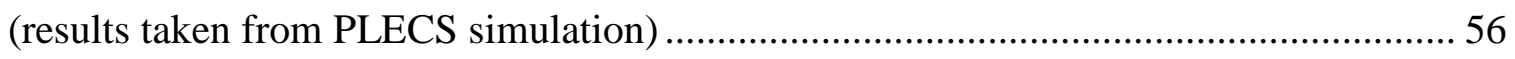

Figure 34: Analytical vs simulation waveforms, $\left[D_{1}, D_{2}, D_{3}\right]=[0.5,0.525,0.525]$ and $\left[\phi_{2}, \phi_{3}\right]=$

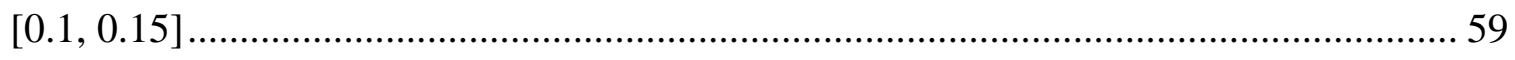


Figure 35: Analytical vs simulation waveforms, $\left[D_{1}, D_{2}, D_{3}\right]=[0.5,0.6,0.525]$ and $\left[\phi_{2}, \phi_{3}\right]=$

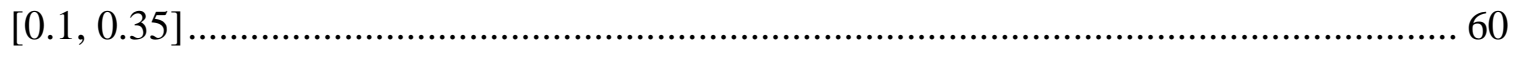

Figure 36: Analytical vs simulation waveforms, $\left[D_{1}, D_{2}, D_{3}\right]=[0.5,0.5,0.5]$ and $\left[\phi_{2}, \phi_{3}\right]=[0.1$,

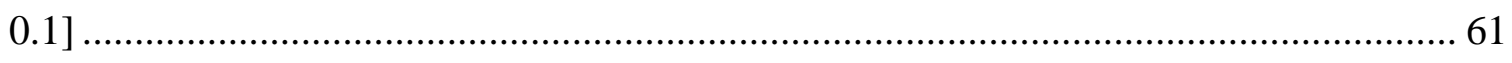

Figure 37: Analytical vs simulation waveforms, $\left[D_{1}, D_{2}, D_{3}\right]=[0.5,0.55,0.55]$ and $\left[\phi_{2}, \phi_{3}\right]=$

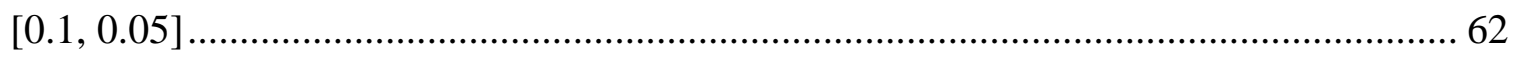

Figure 38: Analytical vs simulation waveforms, $\left[D_{1}, D_{2}, D_{3}\right]=[0.5,0.75,0.75]$ and $\left[\phi_{2}, \phi_{3}\right]=$

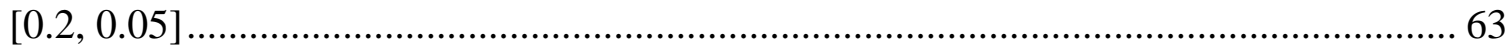




\section{Preface}

Special thanks to Dr. Brandon Grainger for his unparalleled academic support, mentorship, and friendship. My academic development and progress in research is a direct result from his many years of guidance.

A sincere thank you to my fiancée Alexandrea R. Roperti, whose patience and support know no limits. Having publication experience herself, she not only understands the mental commitment required to successfully perform research but also contributed critical feedback throughout the technical writing process. 


\section{Nomenclature}

DAB Dual active bridge

DC Direct current

MMF Magneto motive force

MV Medium voltage

MVDC Medium voltage direct current

ZCS Zero current switching

ZVS Zero voltage switching

$\phi_{x} \quad$ Switching phase shift angle at port $x$ with respect to port 1

$D_{x} \quad$ Duty cycle of switching voltage waveform at port $x$

$f_{s} \quad$ Switching frequency

$n_{x} \quad$ Transformer turns ratio at port $x$

$L_{d c} \quad$ Self-inductance of mutual inductor

$L_{M} \quad$ Mutual inductance of mutual inductor

$V_{x D C} \quad$ DC bus voltage at port $x$

$v_{x} \quad$ Port voltage at port $x$

$i_{x} \quad$ Port current at port $x$

$v_{L x} \quad$ Transformer leakage inductance voltage at port $x$

$V_{\text {armx }} \quad$ Square wave peak voltage for arm voltage at current-fed port $x$

$v_{a r m x-y} \quad$ Square wave voltage for arm $y$ voltage at current-fed port $x$

$v_{\text {armx }} \quad$ Switching voltage waveform for current-fed port $x$ 
$v_{T X} \quad$ Voltage across transformer winding at port $x$

$v_{x D C h 1} \quad$ Voltage across high-side mutual inductor 1 at current-fed port $x$

$v_{x D C h 2} \quad$ Voltage across high-side mutual inductor 2 at current-fed port $x$

$v_{x D C l 1} \quad$ Voltage across low-side mutual inductor 1 at current-fed port $x$

$v_{x D C l 2} \quad$ Voltage across low-side mutual inductor 2 at current-fed port $x$ 


\subsection{Introduction}

Direct Current (DC) distribution systems have matured to the point that DC buses are now a common solution for connecting renewable energy sources and batteries to a primary inverter. Typical applications with DC buses include solar applications with storage and microgrid projects. As the capacity for renewable energy sources within a system continues to develop, it becomes practical to distribute the power at the medium-voltage (MV) level. Unfortunately, issues arise for DC systems at the MV level, especially as individually controlled DC devices are introduced to the system.

One of the challenges associated with adding multiple devices on a shared DC bus is that the complexity of the system control increases as more devices are added to the system, which increases the risk of unstable operation. Therefore, an alternative to the shared DC bus system with individual converters is to use a single multi-port converter to deliver power throughout the DC network [1]. A multi-port converter offers a variety of benefits in comparison to individual converters, including minimized conversion steps, a centralized control scheme, and reduced complexity of power flow management [2]. With such benefits, multi-port converters become appealing in applications requiring multiple converters on the same distribution architecture.

A second challenge introduced as DC system voltages increase is the difficulty in scaling certain converters to MV levels. Recent research in power conversion has identified the Dual Active Bridge (DAB) converter as a highly efficient, easy to control, and scalable design. Most prototypes built for study and experimentation at the medium voltage DC level are voltage-fed DAB converters [3]-[5]. For these reasons, the DAB converter will be the foundation of the power converter introduced in this thesis. 
More recent research has shown that it is possible to create a current-fed DAB using inductors. When compared with voltage-fed DAB converters, the current-fed DAB offers a wide input voltage range, a high step-up ratio, a low input current ripple, a multi-port interface, and DC fault ride-through capability [6], [7]. Studies have already been done to prove the validity of the current-fed DAB for photovoltaic applications [6], [8], [9]. As demonstrated in [10], current-fed DAB converters can achieve $93.4 \%$ efficiency over $91.5 \%$ efficiency of the voltage-fed DAB by adding minimal conduction losses in exchange for reducing switching losses.

Current-fed DAB architectures provide unique challenges when it comes to power flow control. Typically, the power flow control of a voltage-fed, multi-port DAB is achieved based on the assumption that the voltage at each port operates as an ideal square wave [1]. However, the authors have observed that current-fed port voltages can only be approximated as ideal square waves under specific conditions. Thus, in order to achieve accurate control and estimation of power flow from port to port, it must be analytically determined under which conditions the current-fed ports can be expected to have ideal square wave port voltages. For non-ideal square wave port voltage conditions, traditional power flow cannot be used and new power flow equations must be established. The contributions of this thesis is to: first, analytically describe the mutual coupling effects for the multi-port DAB design; and second, analytically determine the conditions for which the multi-port DAB input port voltages can be treated as ideal square waves. 


\subsection{Existing DAB Converter Topologies}

For over 25 years, the DAB converter has been one of the best suited converters for high power DC-DC applications [11]. The inherent soft-switching, galvanic isolation, and bidirectional nature of the $\mathrm{DAB}$ converter provides a strong basic structure from which to develop more complicated converters. Among the more recent complicated forms of the DAB converter, the multi-port $\mathrm{DAB}$ converter and current-fed $\mathrm{DAB}$ converter have both been proven to exhibit additional benefits beyond those of the basic structure.

The traditional $\mathrm{DAB}$ converter is comprised of a full switched bridge on both the primary and secondary side of a high frequency transformer as depicted in Figure 1. The switches create a high frequency AC link between the primary and secondary DC buses. From Faraday's law for inductors, the voltage difference across the transformer leakage inductance induces a change in current equal to

$$
v_{h 1}-v_{h 2}=L \frac{d i_{L}}{d t}
$$

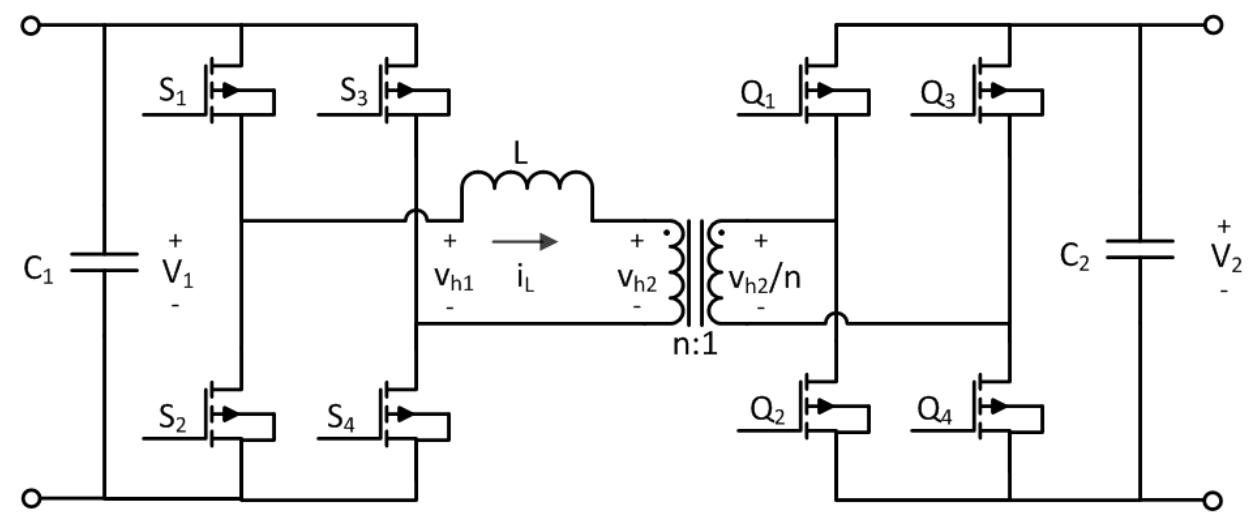

Figure 1: Dual Active Bridge (DAB) Converter 
The switched bridge converts a DC voltage into an AC waveform by providing positive DC voltage during half of a switching period and negative DC voltage during the other half of the switching period. For example, the voltage at the primary DC bus of the DAB converter in Figure 1 is equal to $V_{1}$. When switches $S_{1}$ and $S_{4}$ are $\mathrm{ON}$, the voltage $v_{h 1}$ is equal to $+V_{1}$. Then, for the second half of the switching period, switches $S_{2}$ and $S_{3}$ are $\mathrm{ON}$, which results in $v_{h 1}$ being equal to $-V_{1}$. Zero states can also be added by either having switches $S_{1}$ and $S_{3}$ ON or switches $S_{2}$ and $S_{4} \mathrm{ON}$. The same concept applies for the switching behavior at the secondary DC bus of the DAB converter.

Each switched state governs the voltages $v_{h 1}$ and $v_{h 2}$. The possible switched states are shown below in Figure 2 through Figure 9. Notice that each switching state results in a distinct value for the voltage across the inductor $v_{h 1}-v_{h 2}$. As described in (1), the inductor voltage is directly related to the slope of the inductor current.

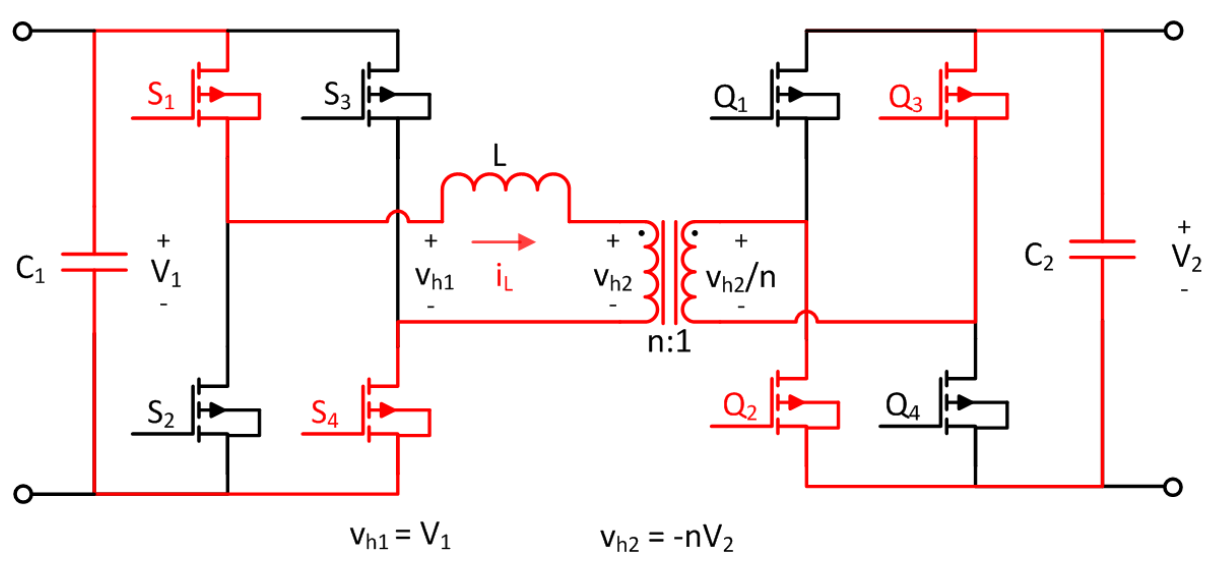

Figure 2: DAB converter current paths with $S_{1}, S_{4}, Q_{2}$, and $Q_{3} \mathrm{ON}$ 


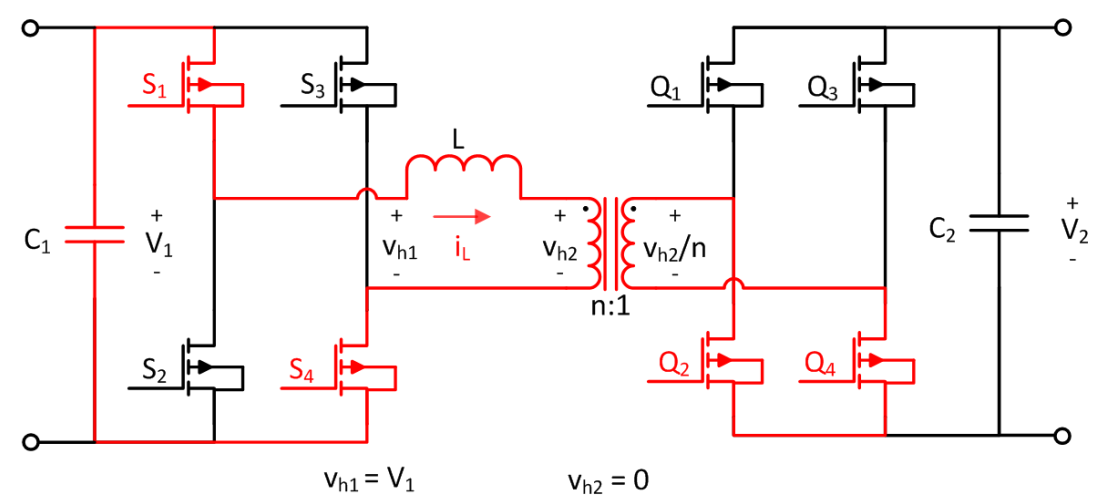

Figure 3: DAB converter current paths with $S_{1}, S_{4}, Q_{2}$, and $Q_{4}$ ON

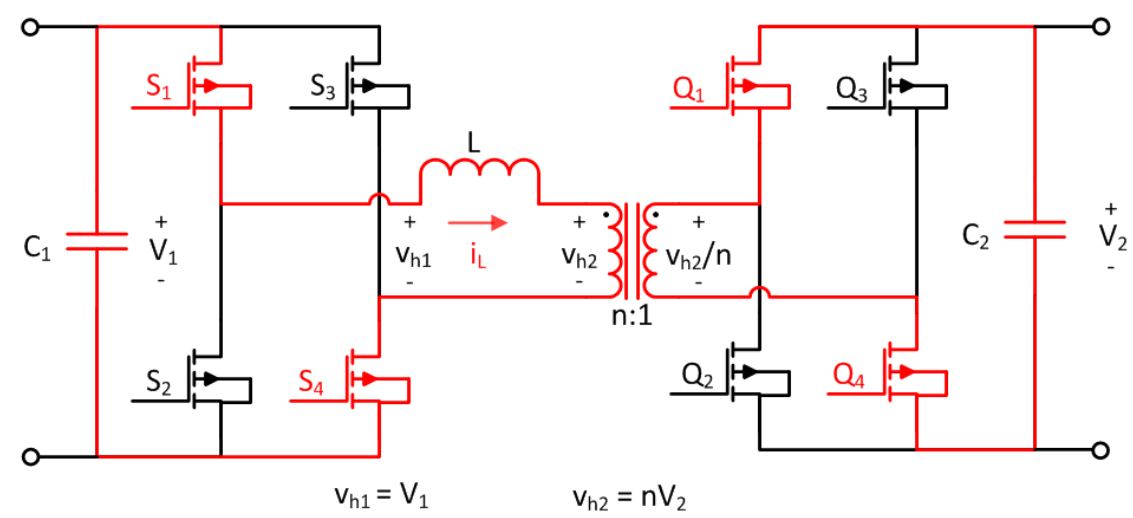

Figure 4: DAB converter current paths with $S_{1}, S_{4}, Q_{1}$, and $Q_{4}$ ON

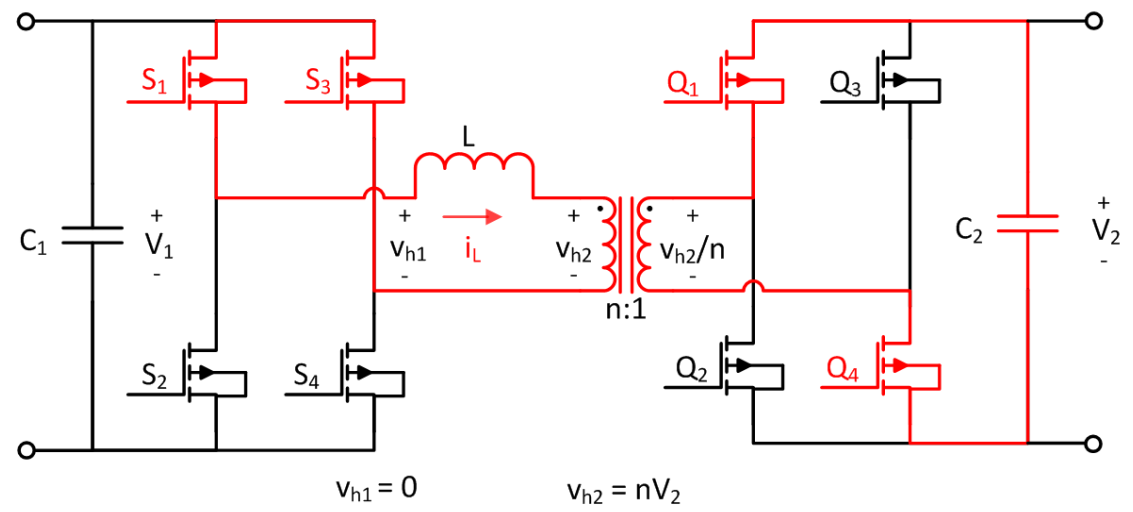

Figure 5: DAB converter current paths with $S_{1}, S_{3}, Q_{1}$, and $Q_{4} \mathrm{ON}$ 


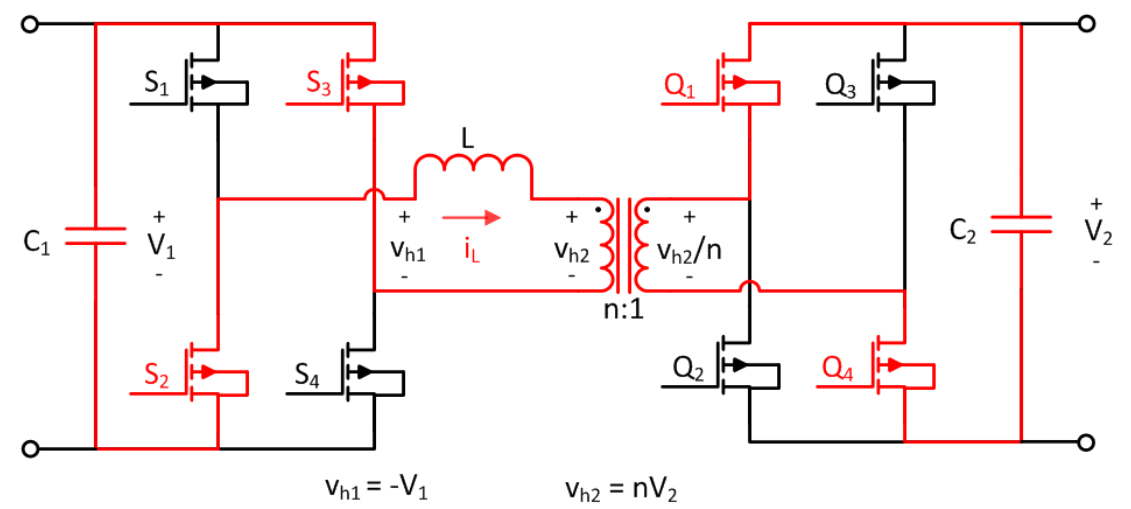

Figure 6: DAB converter current paths with $S_{2}, S_{3}, Q_{1}$, and $Q_{4} \mathrm{ON}$

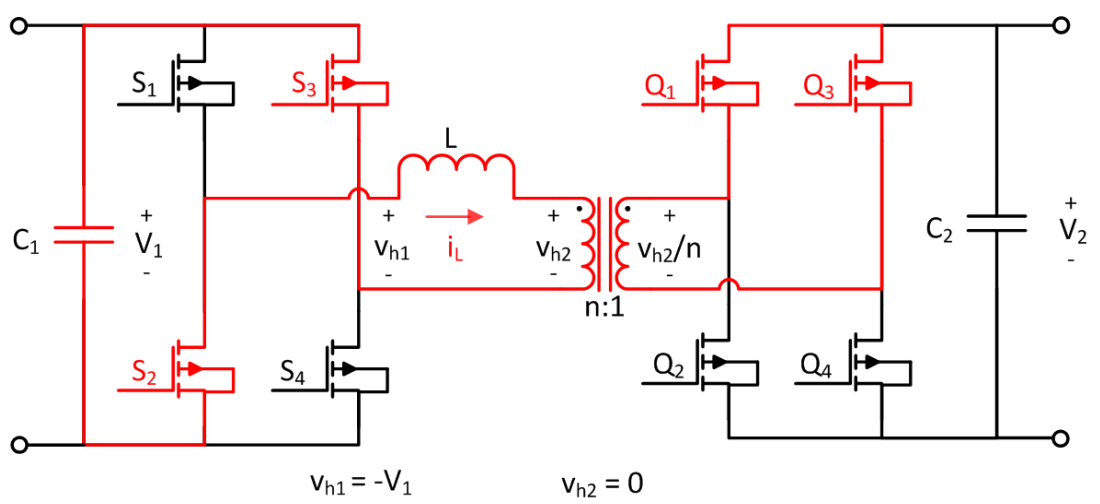

Figure 7: DAB converter current paths with $S_{2}, S_{3}, Q_{1}$, and $Q_{3}$ ON

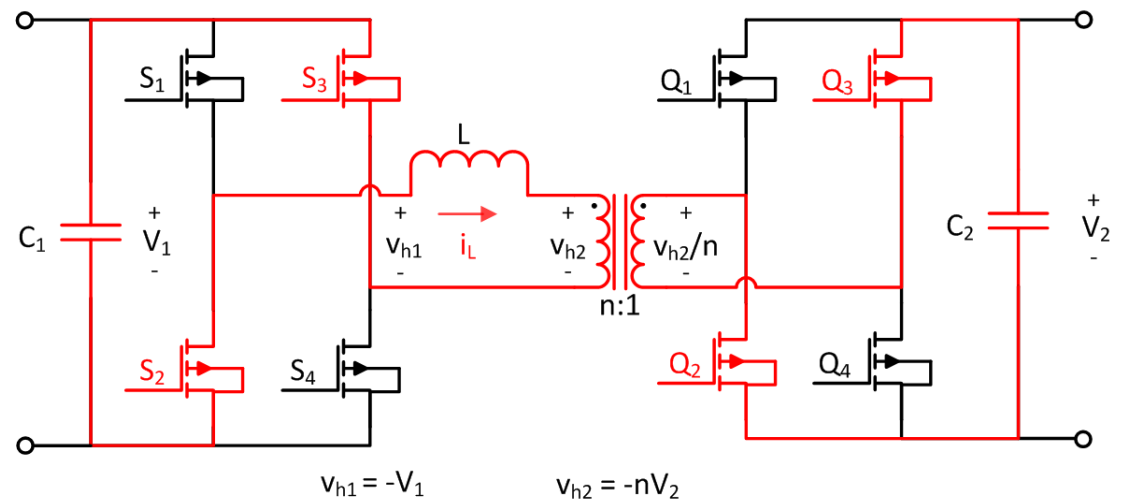

Figure 8: DAB converter current paths with $S_{2}, S_{3}, Q_{2}$, and $Q_{3} \mathrm{ON}$ 


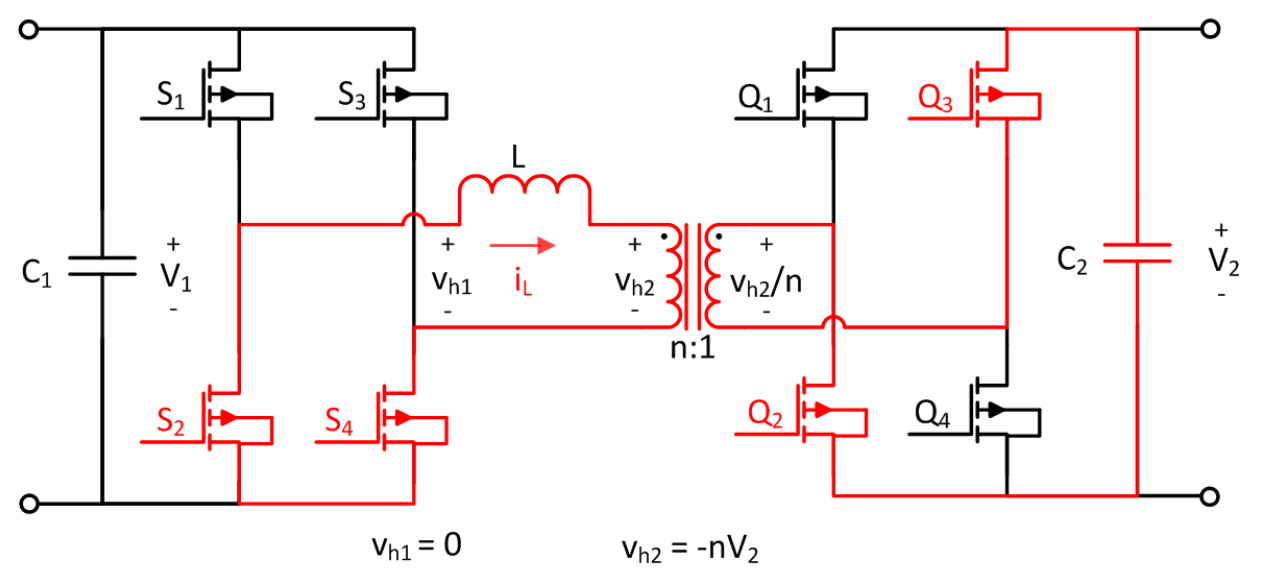

Figure 9: DAB converter current paths with $S_{2}, S_{4}, Q_{2}$, and $Q_{3}$ ON

The traditional methods of controlling the DAB converter are based on the phase shift between the primary and secondary voltage waveforms $v_{h 1}$ and $v_{h 2}$ as shown above in Figure 2 through Figure 9. The four most common methods of phase shift control are depicted in Figure 10 [12]. These methods all contain a phase angle delay between the primary and secondary switched voltages, and that phase angle delay controls the magnitude and direction of power flow. The main difference between these four types of control is the complexity that arises from varying the number and duration of zero states in the voltage waveforms. Each type of switching control affects the primary and secondary voltage waveforms, and in turn, the inductor current waveform. 


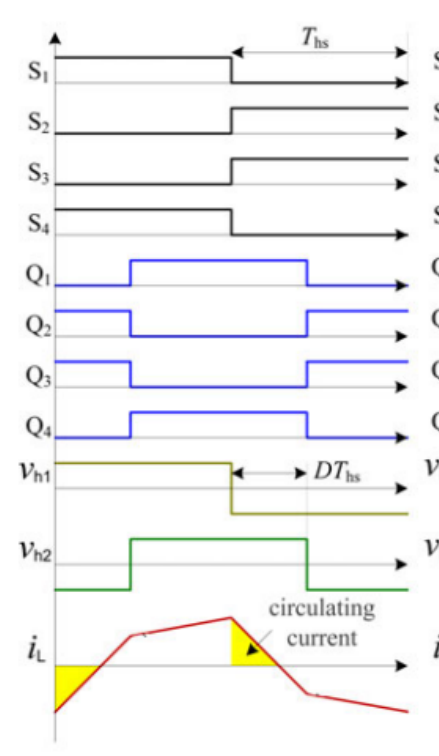

(a)

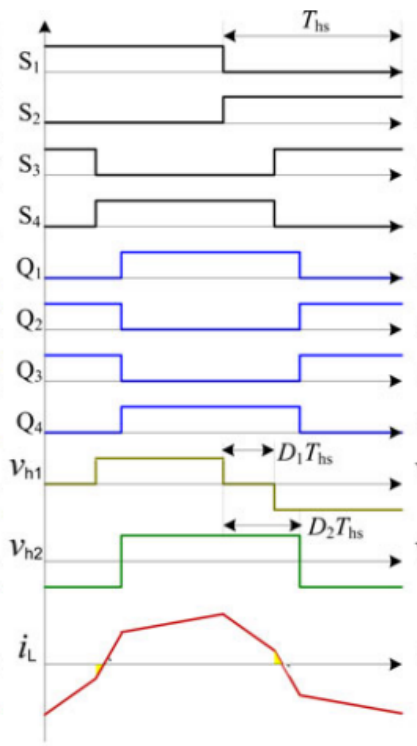

(b)

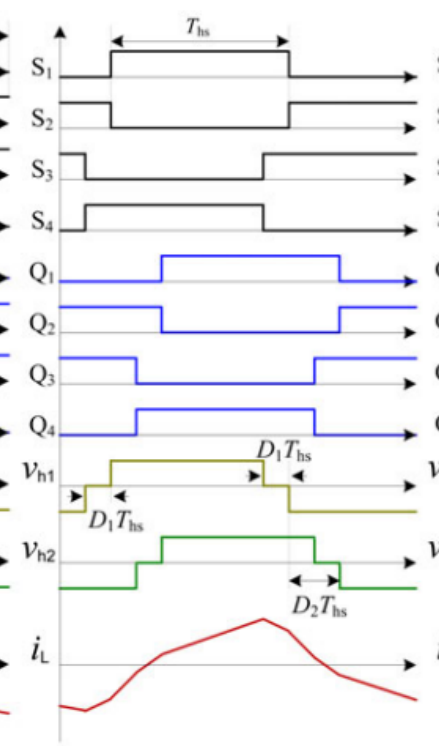

(c)

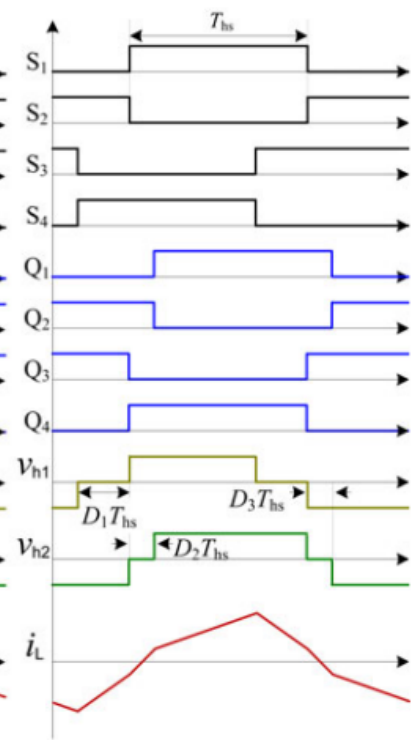

(d)

Figure 10: Single-phase-shift (a), extended-phase-shift (b), dual-phase-shift (c), and triple-phase-shift (d) control [12]

The more complicated versions of the DAB, such as the multi-port DAB and current-fed $\mathrm{DAB}$, operate with the same basic principle as the traditional DAB converter but have slight variations to the circuit layout and control. These converters have features that are desirable within certain applications. In order to understand the current-fed, multi-port DAB converter explored in this thesis, the fundamentals of both the multi-port $\mathrm{DAB}$ converter and the current-fed DAB converter must be defined. 


\subsection{Multi-Port DAB Converter}

The multi-port DAB converter incorporates a multi-winding transformer to deliver power to isolated output circuits. In the context of this thesis, a port is described as the connection of an individual DC network to the multi-winding transformer via a full H-bridge. For example, a threeport converter interconnects three separate DC networks. A three-winding transformer is used to connect each port's full switching bridge with the other bridges. This thesis explores a three-port Dual Active Bridge converter because four-winding transformers and beyond become increasingly complex and impractical for most applications.

The reference three-port Dual Active Bridge (often called TAB) converter circuit shown in Figure 11 is superior to a traditional two-port DAB converter in certain applications. A Zero Voltage Switching (ZVS) and Zero Current Switching (ZCS) performance analysis of the traditional voltage-fed TAB is performed in [13]. As described in the reference analysis, it is possible under certain conditions to achieve ZVS through the entire operating range of the converter, minimizing device stress [13]. Some additional benefits, such as bidirectional power flow and reduction in number of power stages are particularly useful in applications with alternate energy systems with energy storage. From a control standpoint, a system containing multiple converters has a higher potential for instability. By allowing the output of multiple unique voltage levels, the multi-port converter provides an opportunity to centralize control and reduce the number of converters within a DC network. 


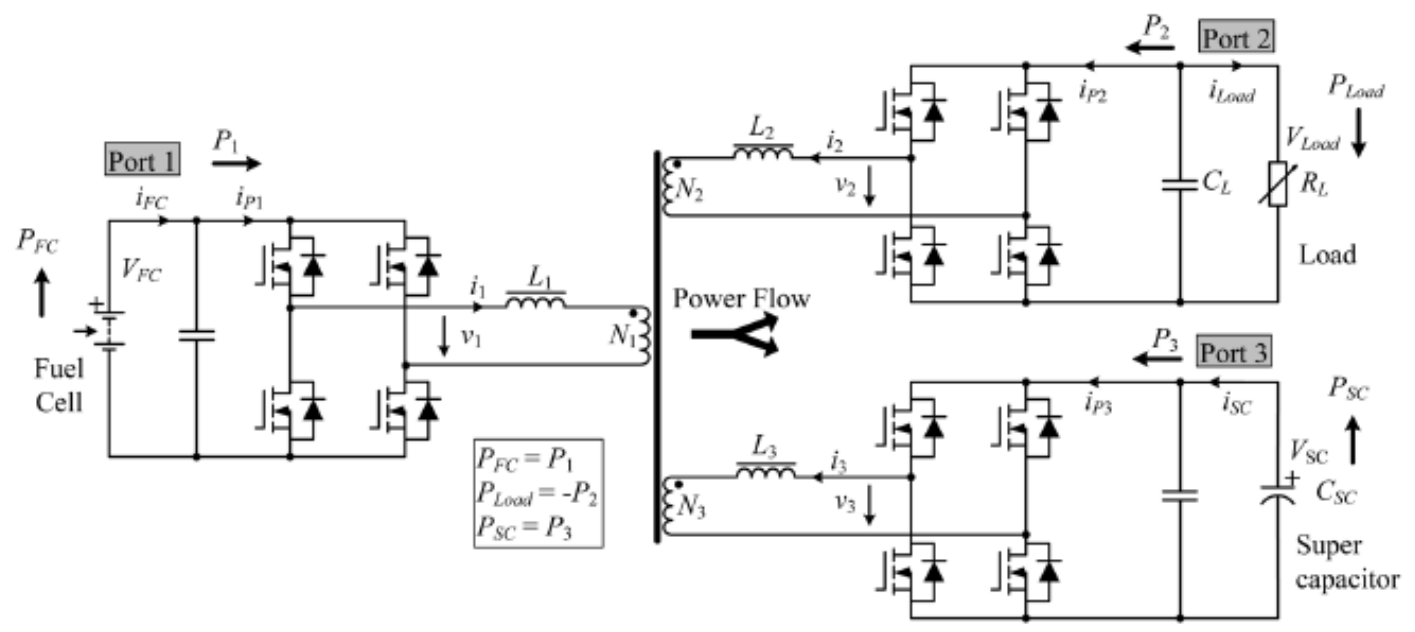

(a)

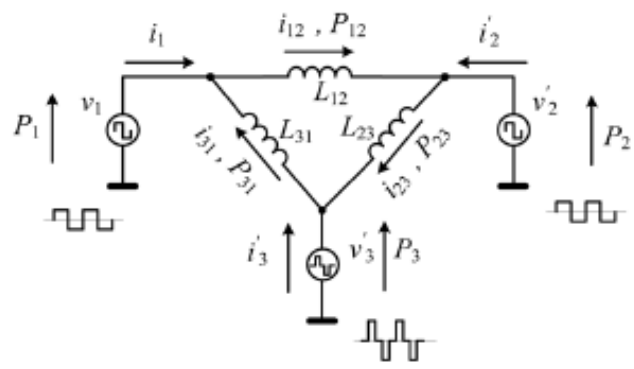

(b)

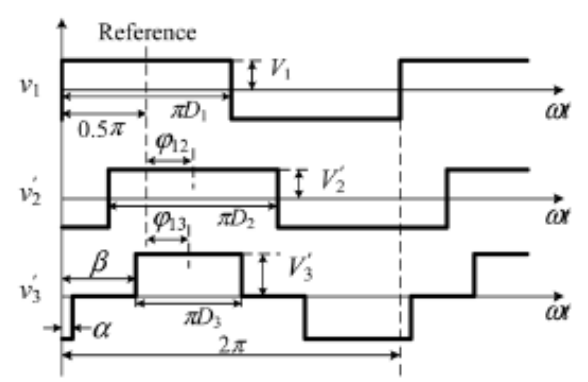

(c)

Figure 11: (a) TAB circuit topology, (b) $\Delta$-equivalent model, and (c) port voltage waveforms [13]

The TAB operates by controlling each switching bridge's phase angle delays, similar to the DAB. In the case of Figure 11, the circuit topology shown in (a) can be simplified to the $\Delta$ equivalent model in (b). Note that the voltage waveforms in (c) show that at each port $v_{1}, v_{2}^{\prime}$, and $v_{3}^{\prime}$ are ideal square waves (with $v_{3}^{\prime}$ containing zero-states). With ideal square waves, the inductor current can easily be calculated from Faraday's law for inductors as in (1). As described in [13], the power transferred from one DC network to another can be computed with the following formula in (2). 


$$
P=\frac{V_{1} V_{2}}{n \omega L} \varphi\left(1-\frac{|\varphi|}{\pi}\right)
$$

Using (2), it is possible to calculate the power transferred between each port $P_{12}, P_{13}$, and $P_{23}$. From there, the total power flow delivered by any port can be calculated with the following equations [13]:

$$
\begin{aligned}
& P_{1}=P_{12}-P_{31} \\
& P_{2}=P_{23}-P_{12} \\
& P_{3}=P_{31}-P_{23}
\end{aligned}
$$

Equations (3)-(5) are power transfer equations for the ideal voltage source condition. These equations will be used later as a benchmark in order to compare the results of the current-fed threeport converter described in section 3.0.

\subsection{Current-Fed DAB Converter}

The second type of advanced DAB converter that is used as a basis for the converter in this thesis is the current-fed DAB converter. It is common practice to add inductance in series with a DC voltage source in order to emulate current source behavior. Typically, this is performed when the source voltage experiences regular fluctuations (for example, fuel cell applications) [14]. Figure 12 illustrates two examples of adding inductance $L$ in series with the DC source of a Dual Active Bridge converter (added before switching and added after switching). Benefits from the 
addition of this inductance include improved ZVS performance, improved overall efficiency, and input voltage flexibility [14].

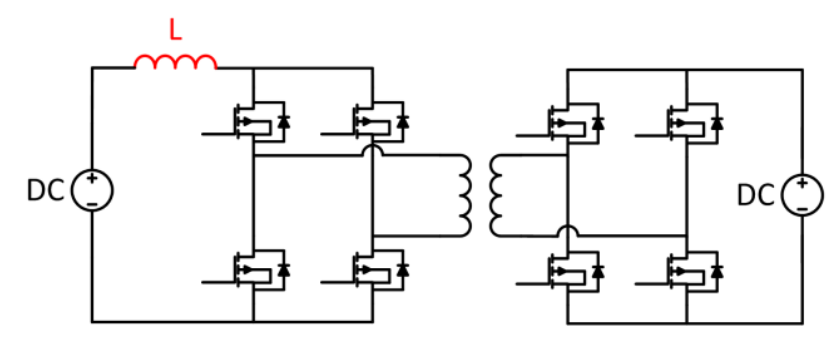

(a)

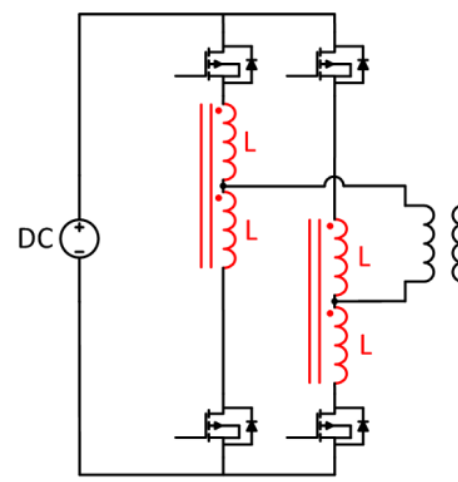

(b)

Figure 12: Current-fed Dual Active Bridge converter designs: (a) Inductance added before switching and (b) inductance added after switching [14]

Note that out of the two possible inductor configurations in Figure 12, the current-fed design explored in this thesis is (b), adding the inductance within the DAB's switches (on the AC side of the DAB converter). This current-fed DAB converter configuration incorporates mutual inductor pairs at each switched node in order to achieve current-fed behavior at its DC bus. By including mutual inductors in the circuit, a port will gain the ability to "ride through" a DC fault without the presence of a DC circuit breaker [15]. The circuit layout of the current-fed converter is shown in Figure 13. 


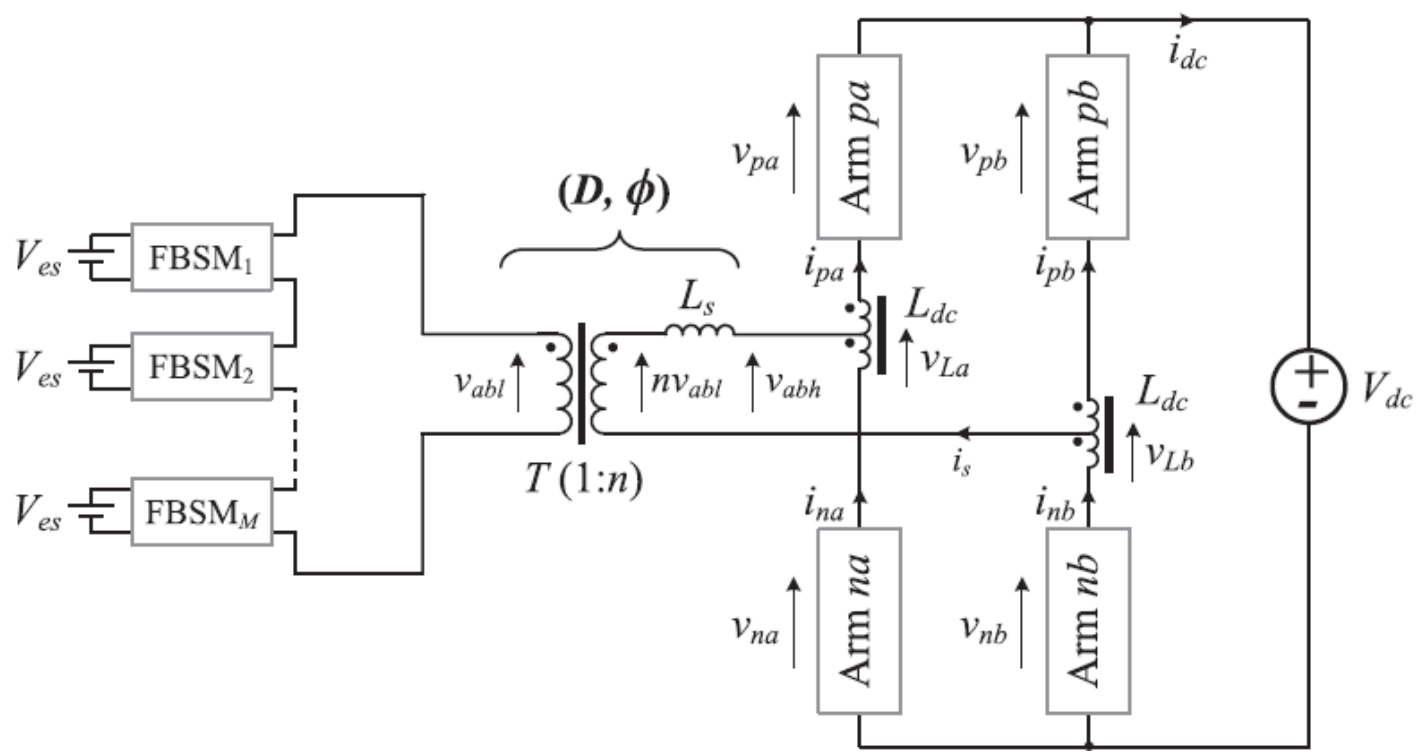

Figure 13: Current-fed DAB Converter [15]

The operation of the current-fed DAB converter is different than the traditional voltagefed converter due to the duty cycle of the switches operating at values larger than $50 \%$. There is no risk of accidentally short-circuiting the DC bus due to the addition of the mutual inductor pairs. In fact, the duty cycle for a current-fed port is a control variable that can be increased to attain a desired output as shown in Figure 14 [15]. 


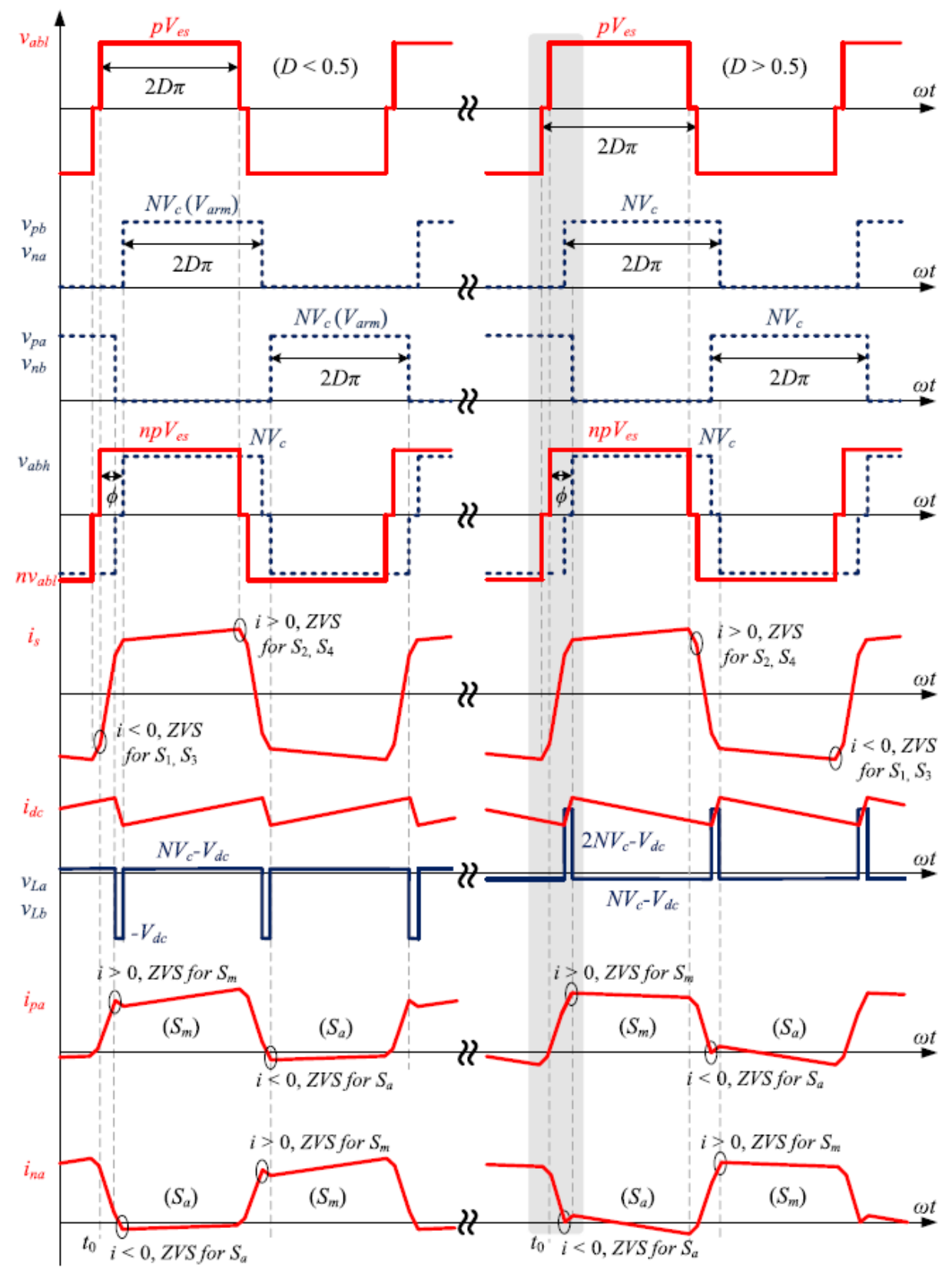

Figure 14: Operational waveforms of current-fed DAB [15] 


\subsection{Multi-Port, Current-Fed DAB Converter Analysis}

The new converter introduced in this thesis is the multi-port, current-fed DAB. As an example application, Figure 15 shows the voltage-fed, LVDC source at the primary port connected to two current-fed, MVDC load ports. The voltage-fed primary port operates in the traditional manner, with the H-bridge switches generating an ideal square wave voltage at $50 \%$ duty cycle or below. The current-fed ports contain a mutual inductor pair at each switching node; therefore, the switching behavior may not result in a square wave for current-fed port voltages $v_{2}$ and $v_{3}$. Characteristic equations defining current-fed port state variables with respect to component size and switching voltage waveforms are defined later in this section. The switching voltage waveforms $v_{1}, v_{a r m 2}$, and $v_{\text {arm } 3}$ used to control the converter are shown in Figure 16. Each waveform has an associated duty cycle $D$ and phase shift $\varphi . v_{\text {arm } 2}$ and $v_{\text {arm } 3}$ will be defined in section 3.1. The generic equations derived in this section hold true for any switching conditions or component values. The example application in Figure 15 will be explored further in section 4.0 . 


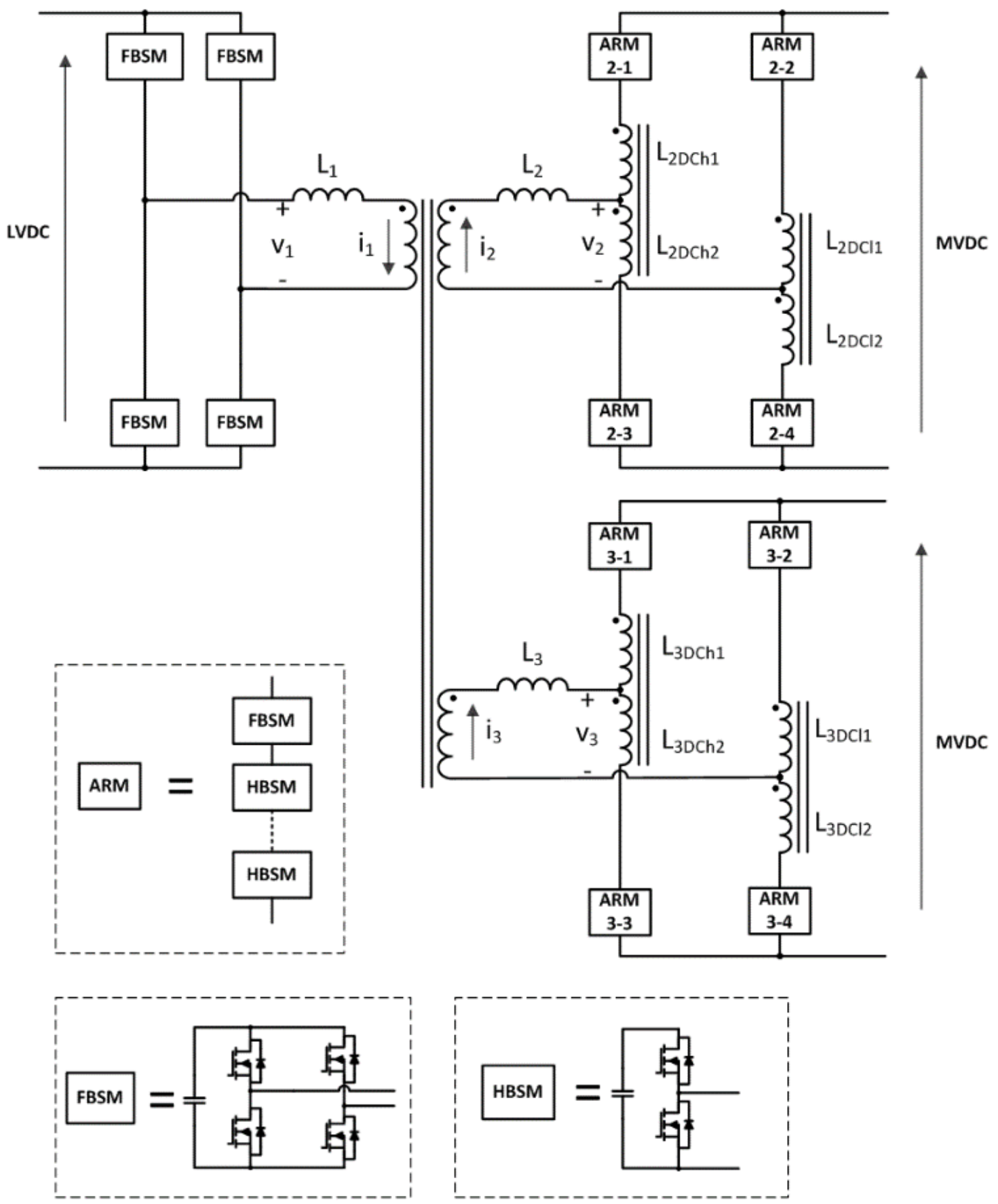

Figure 15: Current-fed, multi-port dual active bridge topology 


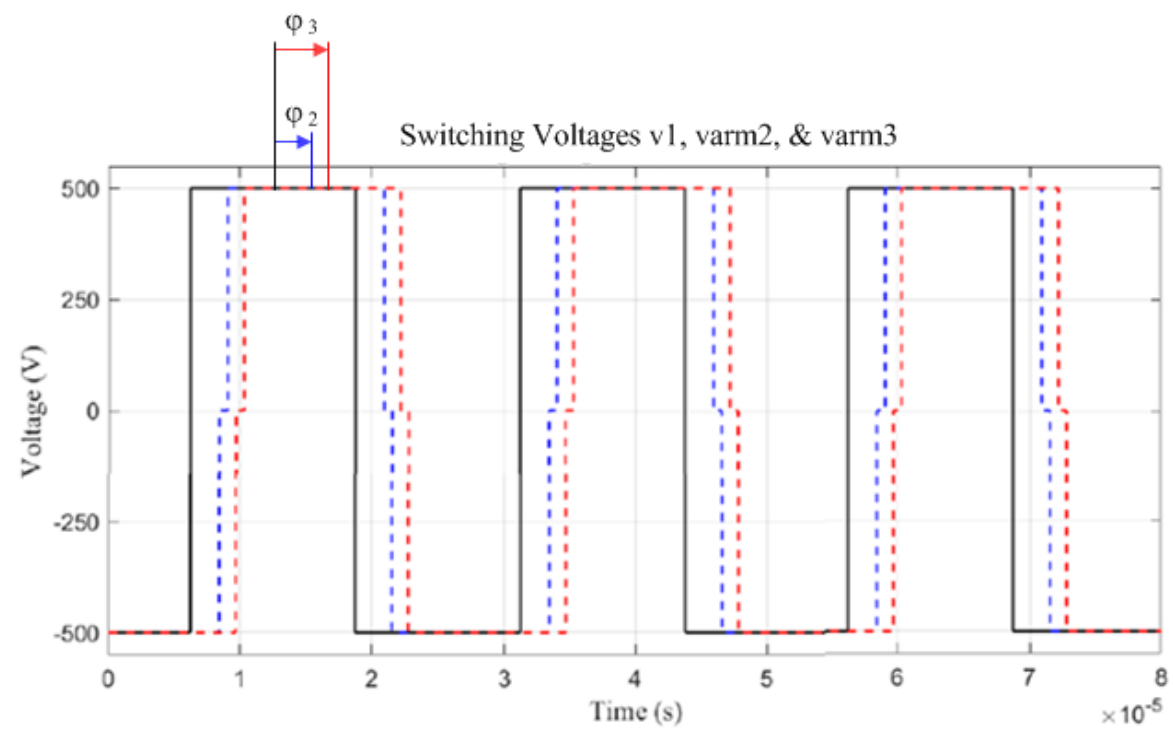

Figure 16: Switching voltage waveforms for each port

\subsection{Characteristic Equations of a Single Port}

In order to analyze Figure 15, first, the behavior of a single port containing mutual inductors (shown in Figure 17) was evaluated. Similar to voltage-fed DAB converters, the power transferred into port 2 in Figure 17 will be the product of the voltage $v_{2}$ and the port current $i_{2}$. After the state variables are defined in terms of known parameters, the power transfer through the entire converter is defined in terms of the parameters at all three ports. 


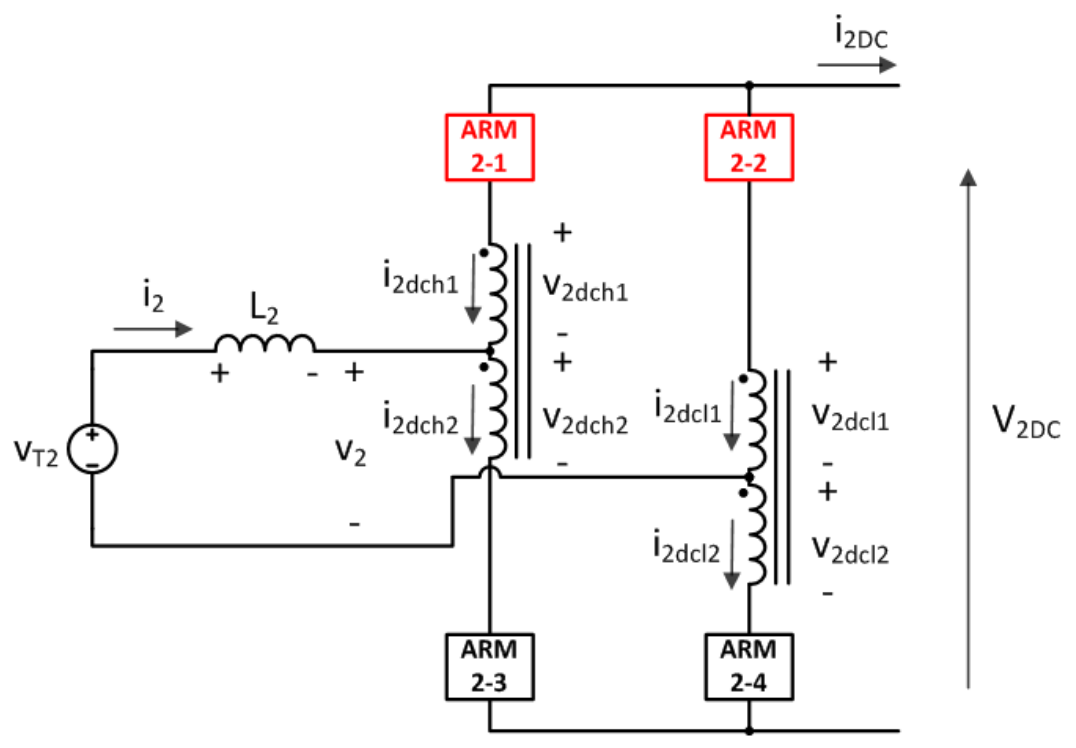

Figure 17: Key parameters of port 2 analysis

At this point, it is most convenient to represent the difference in arm voltages as a single variable, because the resulting waveform is similar to the square wave switching voltage waveform of a typical voltage-fed DAB converter. For port 2, the voltage difference waveform can be defined as

$$
v_{\text {arm } 2}=v_{\text {arm } 2-2}-v_{\text {arm } 2-1}
$$



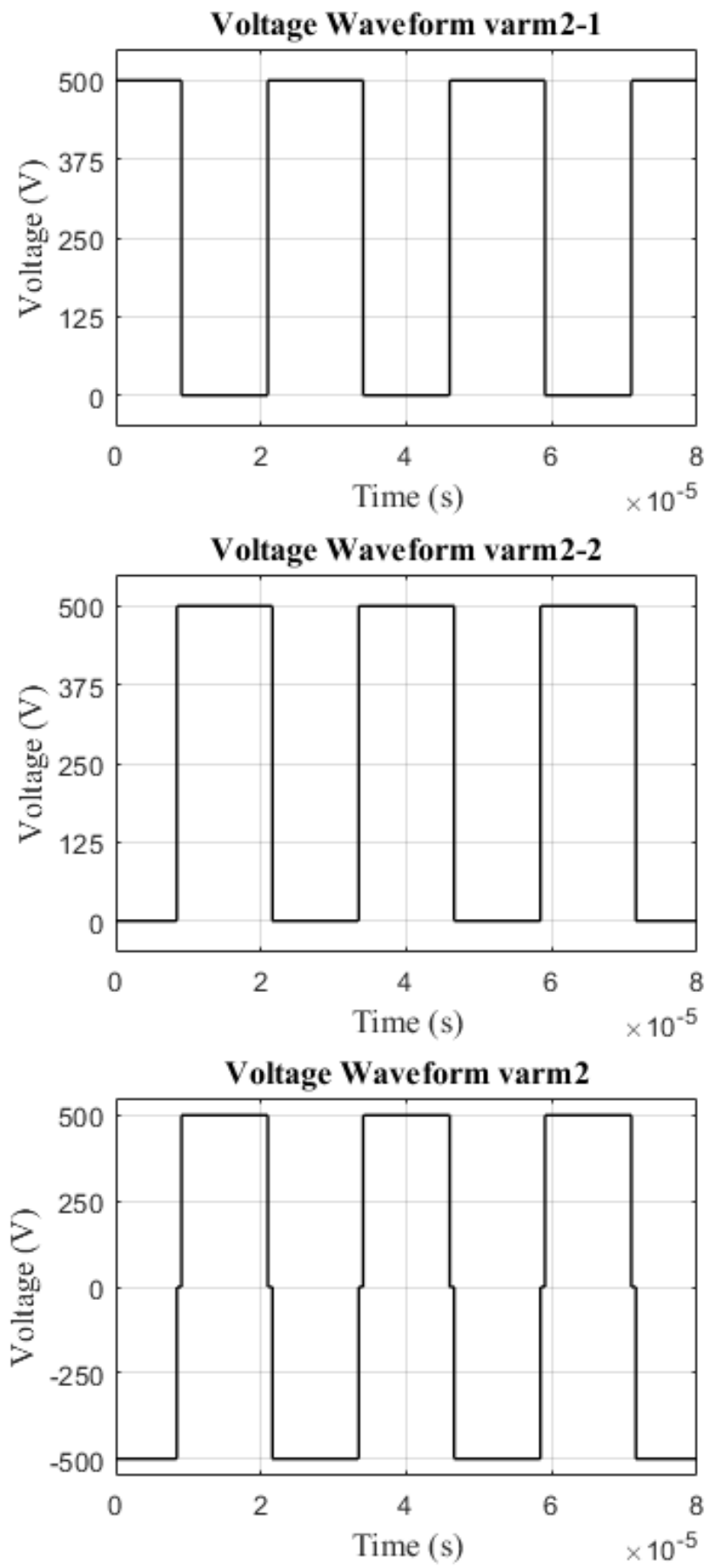

Figure 18: Switching waveforms for upper arms $v_{a r m 2-1}$ and $v_{\text {arm } 2-2}$ and the difference waveform $v_{\text {arm } 2}$ 
Figure 18 shows the switching waveforms for both upper arms (highlighted in red in Figure 17) and the waveform $v_{a r m 2}$ that results from the difference equation (6).

From Figure 17, it is convenient to calculate the current $i_{2}$ through integration of the voltage across the inductor $L_{2}$. Ultimately, voltages $v_{2}$ and $v_{L 2}$ shall completely describe the power transferred into port 2. Note that the voltage across the transformer due to the other ports is simplified to a variable voltage source $v_{T 2}$. The unknown parameters in Figure 17 are $v_{T 2}, v_{L 2}$, $v_{2}, v_{2 d c h 1}, v_{2 d c h 2}, v_{2 d c l 1}$, and $v_{2 d c l 2}$, whereas the known parameters are $v_{\text {arm } 2-1}, v_{\text {arm } 2-2}$, $v_{\text {arm } 2-3}, v_{\text {arm } 2-4}$, and $V_{2 D C}$. Each arm voltage waveform is equal to a square wave with a $50 \%$ duty cycle and a peak value equal to the total voltage stored in the arm capacitors $V_{\text {arm } 2}$ (as shown in Figure 18). The voltage of the DC network $V_{2 D C}$ is likewise a known parameter. Voltage $v_{T 2}$ will be treated as a known parameter for this analysis since it will be used to establish relationships with other ports in Section 3.2. Ultimately, the unknown parameters in Figure 15 will be defined in terms of only the known parameters in order to predict the behavior of current-fed port 2. 


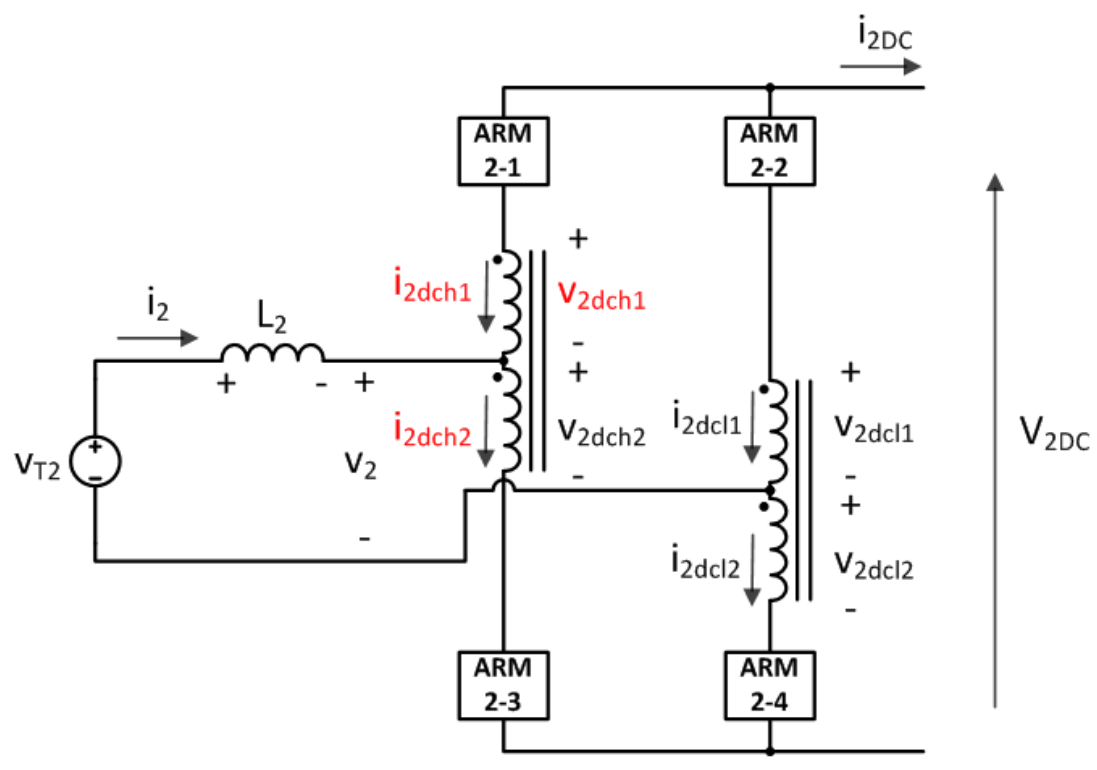

Figure 19: Port 2 analysis - mutual inductor parameters

Physically, the mutual inductor pairs are two adjacent coils sharing a common core. Due to the common flux linking the two inductor coils, the voltage equations at each coil (see Figure 19) are:

$$
\begin{aligned}
& v_{2 d c h 1}=L_{d c} \frac{d i_{2 d c h 1}}{d t}+L_{M} \frac{d i_{2 d c h 2}}{d t}, \\
& v_{2 d c h 2}=L_{d c} \frac{d i_{2 d c h 2}}{d t}+L_{M} \frac{d i_{2 d c h 1}}{d t}, \\
& v_{2 d c l 1}=L_{d c} \frac{d i_{2 d c l 1}}{d t}+L_{M} \frac{d i_{2 d c l 2}}{d t}
\end{aligned}
$$

and,

$$
v_{2 d c l 2}=L_{d c} \frac{d i_{2 d c l 2}}{d t}+L_{M} \frac{d i_{2 d c l 1}}{d t}
$$


Note that the current direction was defined in (7)-(10) in such a way that all terms are positive. It is assumed that all mutual inductors share the same inductance value $L_{d c}$ and mutual inductance $L_{M}$. Through nodal analysis in Figure 20, the current $i_{2}$ is related to the mutual inductor currents by

$$
i_{2}=-i_{2 d c h 1}+i_{2 d c h 2}=i_{2 d c l 1}-i_{2 d c l 2} .
$$

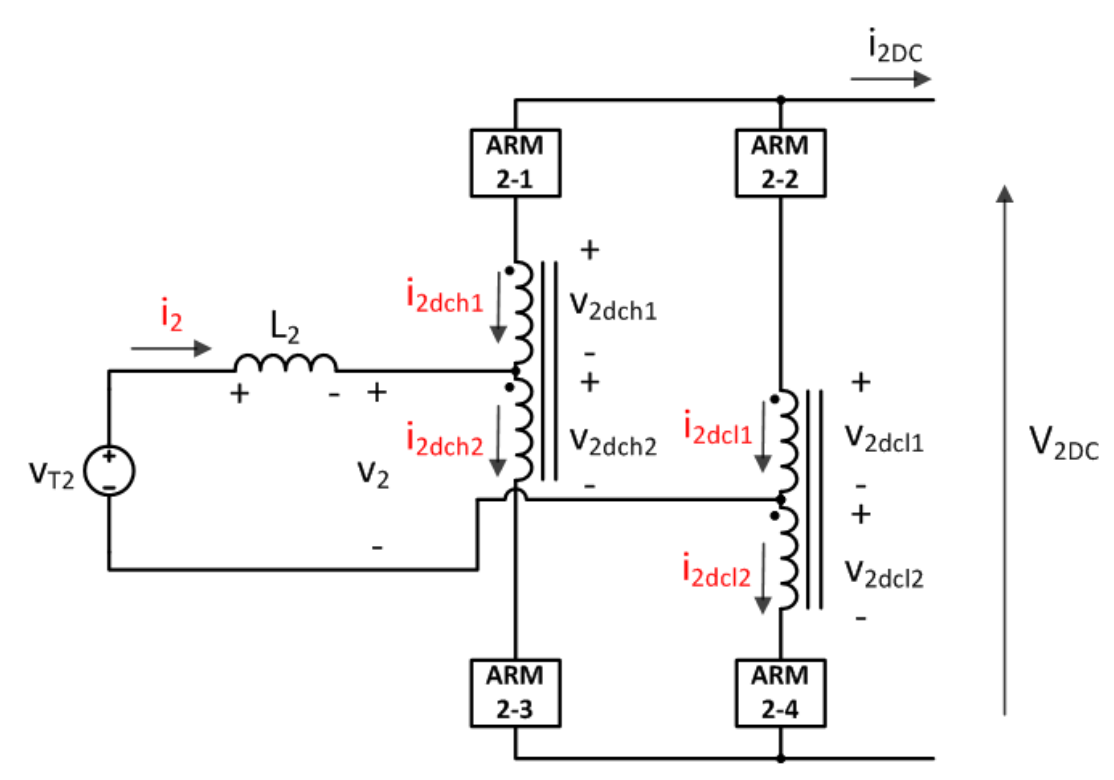

Figure 20: Port 2 anaylsis - nodal analysis of mutual inductor pairs

Since the derivative of the sum of two functions equals the sum of their derivatives, the following derivative relationship of (11) must hold true:

$$
\frac{d i_{2}}{d t}=-\frac{d i_{2 d c h 1}}{d t}+\frac{d i_{2 d c h 2}}{d t}=\frac{d i_{2 d c l 1}}{d t}-\frac{d i_{2 d c l 2}}{d t} .
$$


Using algebraic manipulation and Faraday's law for inductors, (7), (8), and (12) become

$$
\frac{v_{L 2}}{L_{2}}=\frac{1}{L_{d c}-L_{M}}\left(v_{2 d c h 2}-v_{2 d c h 1}\right) .
$$

Similarly, applying Faraday's law to (9), (10), and (12), the relationship becomes:

$$
\frac{v_{L 2}}{L_{2}}=\frac{1}{L_{d c}-L_{M}}\left(v_{2 d c l 1}-v_{2 d c l 2}\right)
$$

Thus, from (13) and (14), it can be shown that

$$
v_{2 d c h 2}-v_{2 d c h 1}=v_{2 d c l 1}-v_{2 d c l 2}
$$

Applying Kirchhoff's voltage law to Figure 20, (15) proves that

$$
v_{2 d c l 2}=v_{2 d c h 1} \text { and } v_{2 d c l 1}=v_{2 d c h 2} \text {. }
$$

Equation (16) is one of the cornerstone equations to understanding the behavior of the circuit. Since arms 1 and 4 and arms 2 and 3 are switched in pairs (which is standard operation for DAB converters), it is also known that

$$
v_{\text {arm } 2-4}=v_{\text {arm } 2-1} \text { and } v_{\text {arm } 2-2}=v_{\text {arm } 2-3}
$$

Using the relationships in (14)-(16), Kirchhoff's voltage law can be applied once more to Figure 20 to solve for $v_{2 d c h 1}$ and $v_{2 d c l 1}$.

$$
\begin{gathered}
v_{2 d c h 1}=\left(v_{a r m 2}-v_{T 2}\right)\left(\frac{L_{d c}-L_{M}}{L_{2}+L_{d c}-L_{M}}\right)+v_{2 d c l 1} \\
v_{2 d c l 1}=-\left(v_{a r m 2}-v_{T 2}\right)\left(\frac{L_{d c}-L_{M}}{L_{2}+L_{d c}-L_{M}}\right)+v_{2 d c h 1}
\end{gathered}
$$

From (13), (18), and (19), it is possible to define the transformer leakage inductance voltage expressed in terms of known voltage values. 


$$
v_{L 2}=\left(\frac{L_{2}}{L_{2}+L_{d c}-L_{M}}\right)\left(v_{T 2}-v_{a r m 2}\right)
$$

The voltage across the transformer leakage inductance in (20) will be used later in conjunction with Faraday's law for inductors to define the current flowing through each current-fed port.

Only voltages $v_{2}$ and $v_{L 2}$ are required to describe the power transferred into port 2. Applying Kirchhoff's voltage law to Figure 21 , the voltage $v_{2}$ can be defined as

$$
v_{2}=\left(\frac{L_{d c}-L_{M}}{L_{2}+L_{d c}-L_{M}}\right) v_{T 2}+\left(\frac{L_{2}}{L_{2}+L_{d c}-L_{M}}\right) v_{a r m 2}
$$

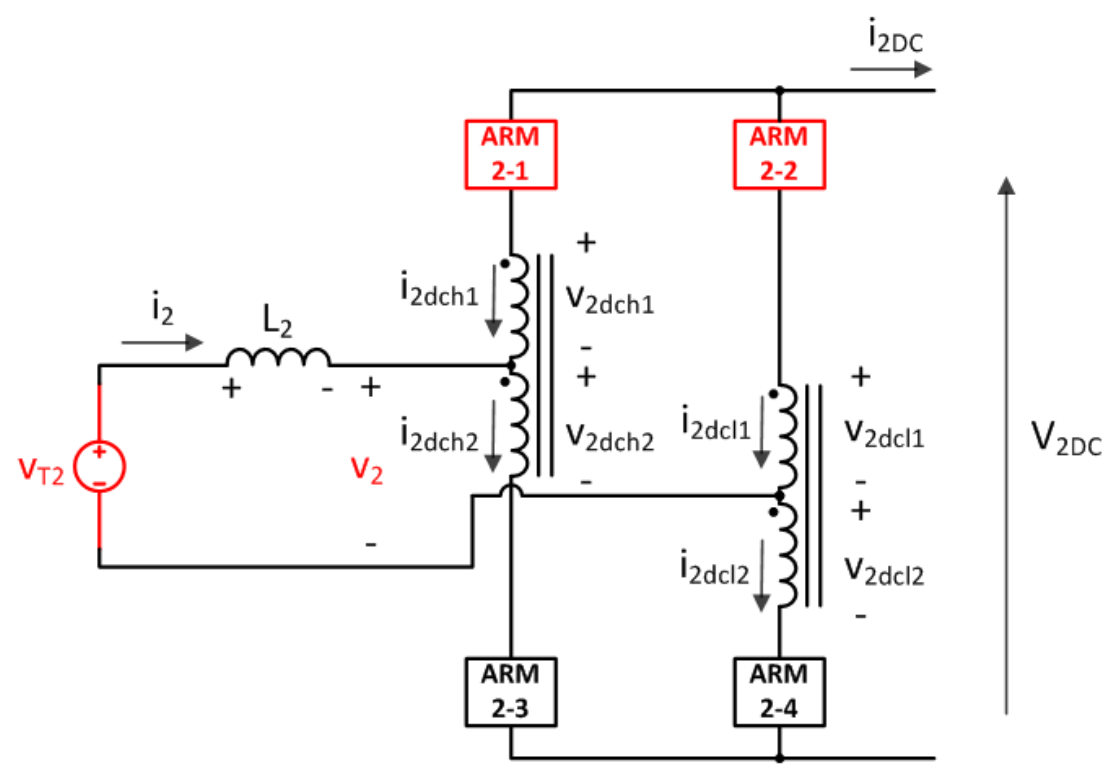

Figure 21: Port 2 analysis - port voltage $v_{2}$ in terms of controllable parameters $v_{T 2}$ and $v_{\text {arm } 2}$

From (21) it can be inferred that if the transformer leakage inductance $L_{2}$ is much larger than the mutual inductance $\left(L_{D C}-L_{M}\right)$, the voltage $v_{2}$ will be equal to the switching voltage waveform $v_{\text {arm2 }}$. Conversely, if $L_{2}$ is much smaller than $\left(L_{D C}-L_{M}\right)$, the voltage $v_{2}$ will equal the 
transformer voltage $v_{T 2}$. Section 5.0 discusses the effects of inductor size on converter performance.

\subsection{Analysis of the 3-Port Converter}

The following section relates the port voltage and leakage inductor voltage of the single port solved above to the remaining ports within the converter. The simplified diagram of the 3port system is shown in Figure 22. Note that $v_{1}$ is an equivalent square wave voltage source representing the low voltage DC source being switched by a full bridge. Ultimately, the port voltages $v_{1}, v_{2}$, and $v_{3}$ and currents $i_{1}, i_{2}$, and $i_{3}$ shall be defined in order to establish power flow equations.

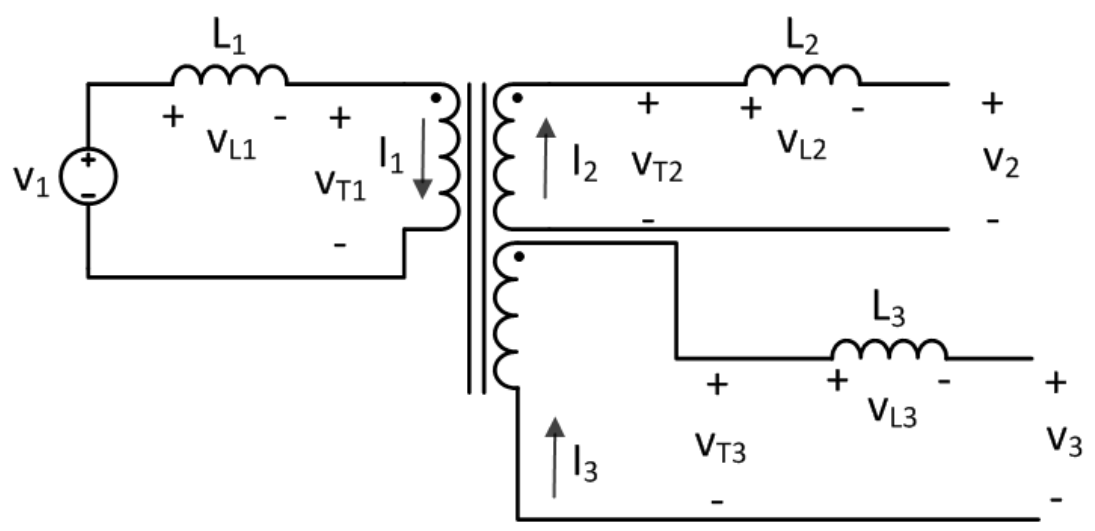

Figure 22: Key parameters of the 3-port converter 
Establishing the equations of a multi-winding transformer, it is known from Faraday's law of mutual induction that the Volts-per-turn of each winding is equal. Therefore,

$$
\frac{v_{T 1}}{n_{1}}=\frac{v_{T 2}}{n_{2}}=\frac{v_{T 3}}{n_{3}}
$$

Total MMF in a multi-winding transformer is the magnetic analog to Kirchhoff's current law; thus,

$$
n_{1} i_{1}=n_{2} i_{2}+n_{3} i_{3}
$$

Since the derivative of the sum of two functions equals the sum of their derivatives, the following derivative relationship of (19) must hold true:

$$
n_{1} \frac{d i_{1}}{d t}=n_{2} \frac{d i_{2}}{d t}+n_{3} \frac{d i_{3}}{d t}
$$

Applying Kirchhoff's current law to Figure 22 and Faraday's law to the derivatives of the leakage inductor currents, (20) becomes

$$
n_{1} \frac{v_{1}-v_{T 1}}{L_{1}}=n_{2} \frac{v_{T 2}-v_{2}}{L_{2}}+n_{3} \frac{v_{T 3}-v_{3}}{L_{3}} .
$$

The port voltages at any current-fed port can be expressed in terms of arm voltages and the voltage at the transformer as shown in (17). Through algebraic manipulation and simplification of (17) and (21), it is possible to express current-fed port voltages in terms of the arm voltage waveforms and the source voltage $v_{1}$ as shown in (22) and (23):

$$
v_{2}=K_{\beta 2} \frac{n_{1}}{L_{1}} v_{1}+\frac{K_{\beta 2} n_{2}+L_{2}}{L_{\alpha 2}} v_{a r m 2}+K_{\beta 2} \frac{n_{3}}{L_{\alpha 3}} v_{a r m 3}
$$


and

$$
v_{3}=K_{\beta 3} \frac{n_{1}}{L_{1}} v_{1}+K_{\beta 3} \frac{n_{2}}{L_{\alpha 2}} v_{a r m 2}+\frac{K_{\beta 3} n_{3}+L_{3}}{L_{\alpha 3}} v_{a r m 3}
$$

Similarly, the voltage across the inductors can be expressed as:

$$
\begin{gathered}
v_{L 1}=\frac{L_{1}-K n_{1}^{2}}{L_{1}} v_{1}-\frac{K n_{1} n_{2}}{L_{\alpha 2}} v_{a r m 2}-\frac{K n_{1} n_{3}}{L_{\alpha 3}} v_{a r m 3}, \\
v_{L 2}=\frac{L_{2}}{L_{\alpha 2}}\left(\frac{K n_{1} n_{2}}{L_{1}} v_{1}+\frac{K n_{2}^{2}-L_{\alpha 2}}{L_{\alpha 2}} v_{a r m 2}+\frac{K n_{2} n_{3}}{L_{\alpha 3}} v_{a r m 3}\right),
\end{gathered}
$$

and,

$$
v_{L 3}=\frac{L_{3}}{L_{\alpha 3}}\left(\frac{K n_{1} n_{3}}{L_{1}} v_{1}+\frac{K n_{2} n_{3}}{L_{\alpha 2}} v_{a r m 2}+\frac{K n_{3}^{2}-L_{\alpha 3}}{L_{\alpha 3}} v_{a r m 3}\right) .
$$

The constants in (22)-(26) are equal to:

$$
\begin{gathered}
L_{\alpha 2}=L_{2}+L_{d c}-L_{M}, \\
L_{\alpha 3}=L_{3}+L_{d c}-L_{M}, \\
K=\frac{L_{1} L_{\alpha 2} L_{\alpha 3}}{n_{1}^{2} L_{\alpha 2} L_{\alpha 3}+n_{2}^{2} L_{1} L_{\alpha 3}+n_{3}^{2} L_{1} L_{\alpha 2}}, \\
K_{\beta 2}=K n_{2}\left(\frac{L_{d c}-L_{M}}{L_{\alpha 2}}\right),
\end{gathered}
$$

and,

$$
K_{\beta 3}=K n_{3}\left(\frac{L_{d c}-L_{M}}{L_{\alpha 3}}\right)
$$


Now that the key voltage relationships in Figure 22 are defined by (22)-(26), the power transfer across the converter can be analytically determined. Currents can be directly derived from Faraday's law:

$$
i_{1}=\int \frac{v_{L 1}}{L_{1}} d t ; \quad i_{2}=\int \frac{v_{L 2}}{L_{2}} d t ; \quad i_{3}=\int \frac{v_{L 3}}{L_{3}} d t
$$

Also, power transfer is expressed as:

$$
P_{1}=v_{1} i_{1} ; \quad P_{2}=v_{2} i_{2} ; \quad P_{3}=v_{3} i_{3} .
$$

Finally, through power balance,

$$
P_{1}=P_{2}+P_{3} .
$$

Note that power flow is often expressed in terms of duty cycle $D$ and phase shift $\varphi$ without the need for integration. Due to the increased number of operating modes of a 3-port converter when compared to a 2-port converter, that simplification cannot be performed within the scope of this thesis. 


\subsection{PLECS Simulation}

In order to confirm the accuracy of the characteristic equations, a PLECS simulation was developed. The circuit model of the current-fed, three-port DAB converter is shown in Figure 23 with the submodule details provided in Figure 24 through Figure 26. The primary voltage source is modeled as an ideal square wave voltage source. The secondary and tertiary DC buses were treated as ideal voltage sources feeding a resistive load. The secondary and tertiary ports also contain submodule blocks which include the mutual inductor pairs and arm modules. The numerous voltmeters and ammeters captured waveforms that are later used to explore the behavior of the converter. 


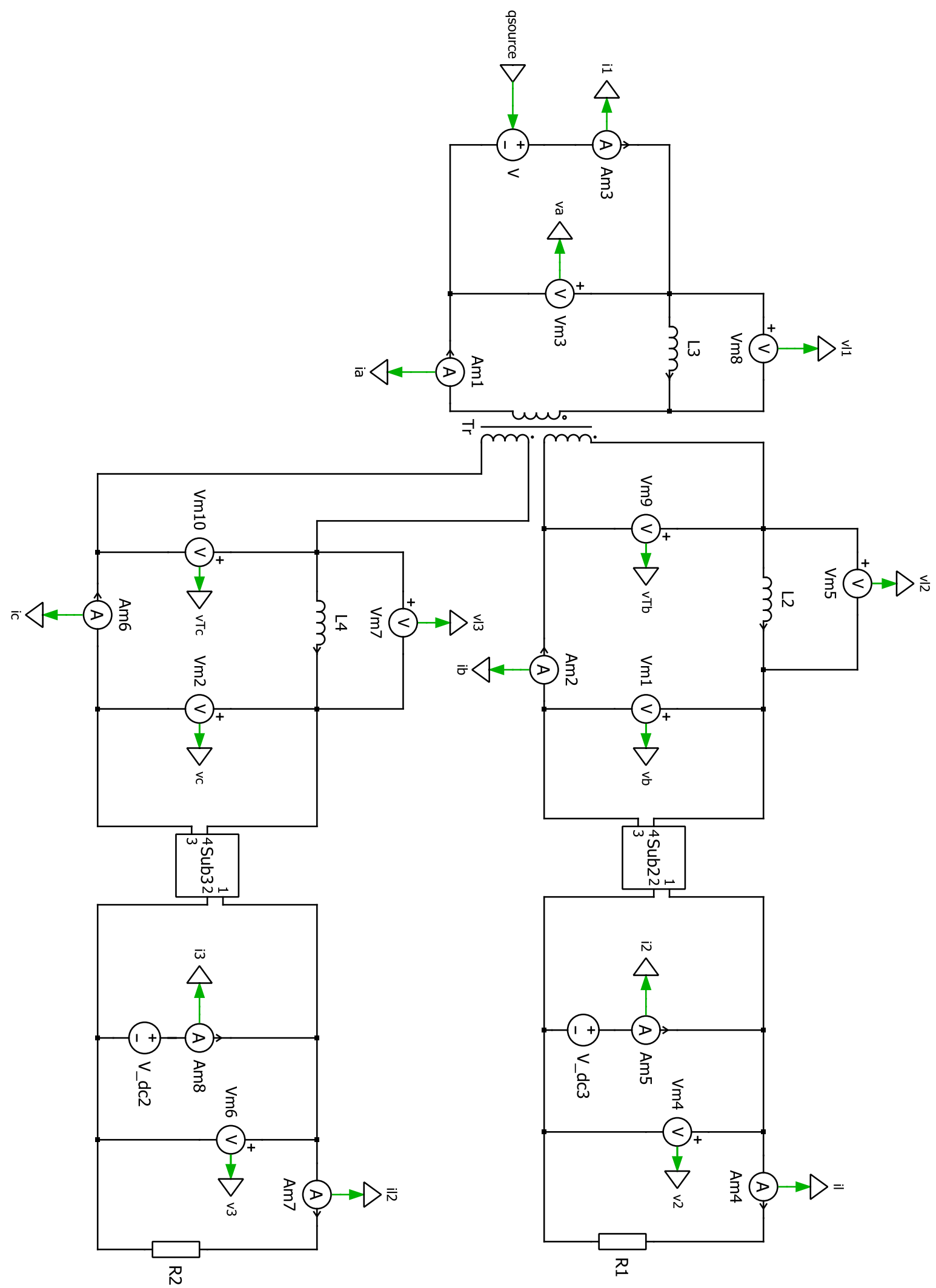

Figure 23: PLECS circuit model of current-fed three-port DAB converter 


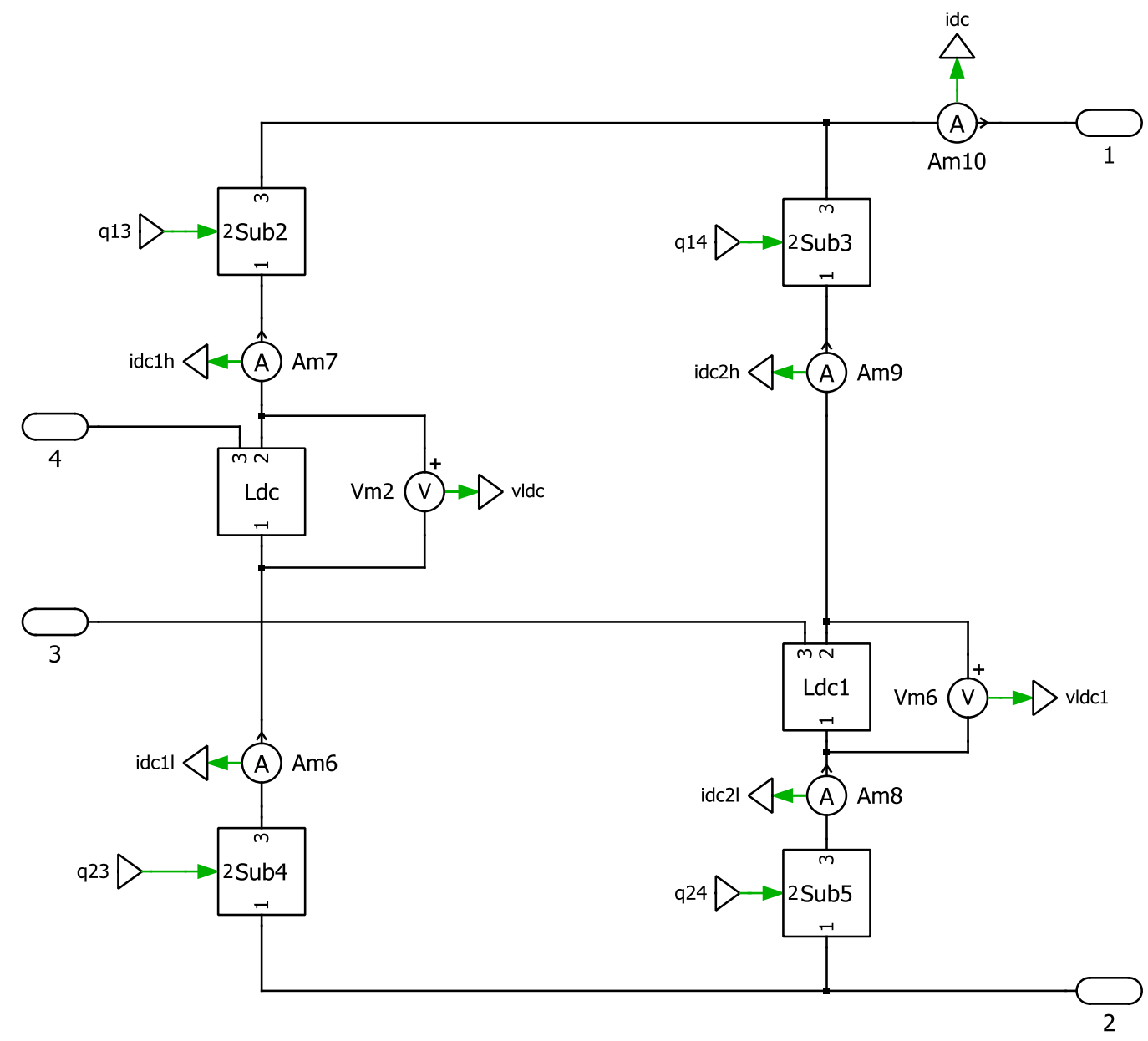

Figure 24: Current-fed switching submodule $S u b 2$ and $S u b 3$

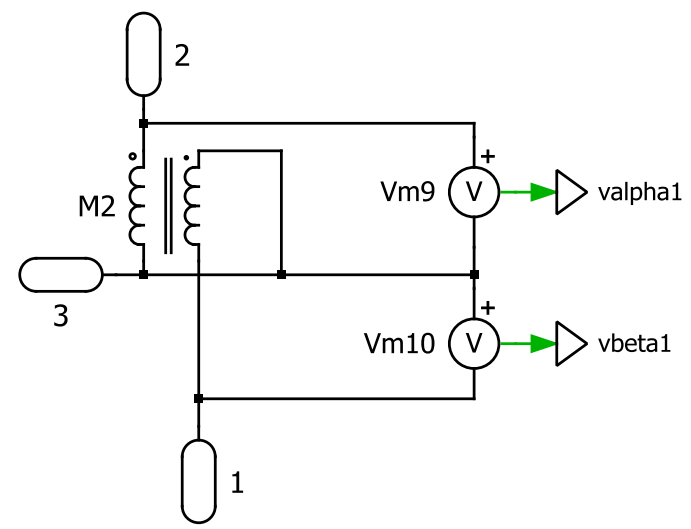

Figure 25: Mutual inductor submodule $L d c$ and $L d c 1$ 


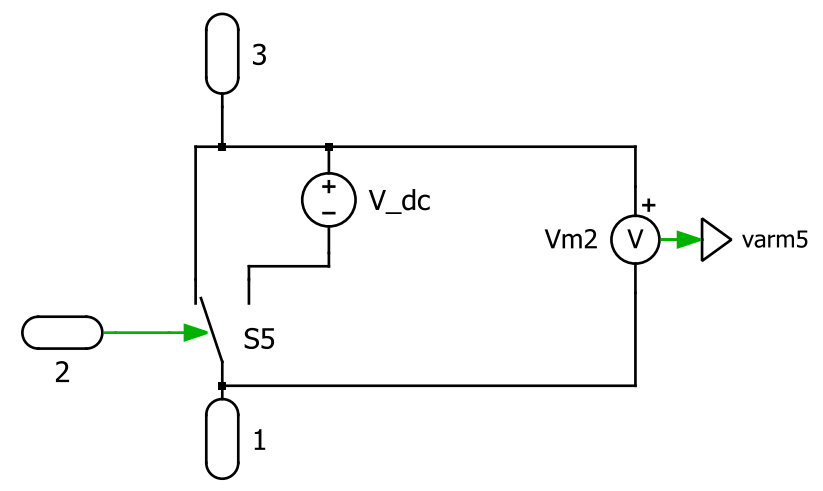

Figure 26: Arm switching submodule $S u b 2$ through $S u b 5$

Circuit component values were chosen based upon the values from a reference experiment of a current-fed DAB [7]. The reference experiment proved that fault tolerance can be achieved for a converter with the same parameter values. Table I includes the parameters that were used for both the calculations and the simulation.

Table 1: Circuit Parameters

\begin{tabular}{|c|c|c|c|c|c|}
\hline Parameter & Variable & Value & Parameter & Variable & Value \\
\hline Primary Turns Ratio & $n_{1}$ & 1 & Primary Duty Cycle & $D_{1}$ & 0.5 \\
\hline Secondary Turns Ratio & $n_{2}$ & 1 & Secondary Duty Cycle & $D_{2}$ & 0.525 \\
\hline Tertiary Turns Ratio & $n_{3}$ & 1 & Tertiary Duty Cycle & $D_{3}$ & 0.525 \\
\hline Primary Winding Inductance & $L_{1}$ & $20 \mu \mathrm{H}$ & Secondary Switching Delay (p.u.) & $\phi_{2}$ & 0.10 \\
\hline Secondary Winding Inductance & $L_{2}$ & $20 \mu \mathrm{H}$ & Tertiary Switching Delay (p.u.) & $\phi_{3}$ & 0.15 \\
\hline Tertiary Winding Inductance & $L_{3}$ & $20 \mu \mathrm{H}$ & Primary DC Voltage & $V_{1 D C}$ & $500 \mathrm{~V}$ \\
\hline Coupled Inductor Inductance & $L_{d c}$ & $100 \mu \mathrm{H}$ & Secondary DC Voltage & $V_{2 D C}$ & $525 \mathrm{~V}$ \\
\hline Mutual Inductance & $L_{M}$ & $80 \mu \mathrm{H}$ & Tertiary DC Voltage & $V_{3 D C}$ & $525 \mathrm{~V}$ \\
\hline Switching Frequency & $\boldsymbol{f}_{s}$ & $40 \mathrm{kHz}$ & Secondary Arm Voltage & $V_{\text {arm } 2}$ & $500 \mathrm{~V}$ \\
\hline Switching Period & $T_{\mathbf{s}}$ & $25 \mu \mathrm{s}$ & Tertiary Arm Voltage & $V_{\text {arm } 3}$ & $500 \mathrm{~V}$ \\
\hline
\end{tabular}


Recall that for simplification of the analyses, each arm was treated as a single submodule. Therefore, each arm voltage either has its capacitor switched in series (positive voltage) or the capacitor bypassed (zero Volts), which results in a square wave. Note that arm2-1 and $\operatorname{arm}_{2-4}$ switch as a pair; likewise, arm2-2 and arm2-3 switch as a pair. Also, as the duty cycle of the arms extend beyond 0.5 , the voltage difference waveform $v_{\text {arm } 2}$ will have zero states as if it were operating with a duty cycle below 0.5 . The same switching behavior occurs for current-fed port 3 , except that the phase shift $\phi_{3}$ is different than the phase shift of port $2, \phi_{2}$. Figure 27 shows the arm voltages and difference waveform for current-fed ports 2 and 3. 

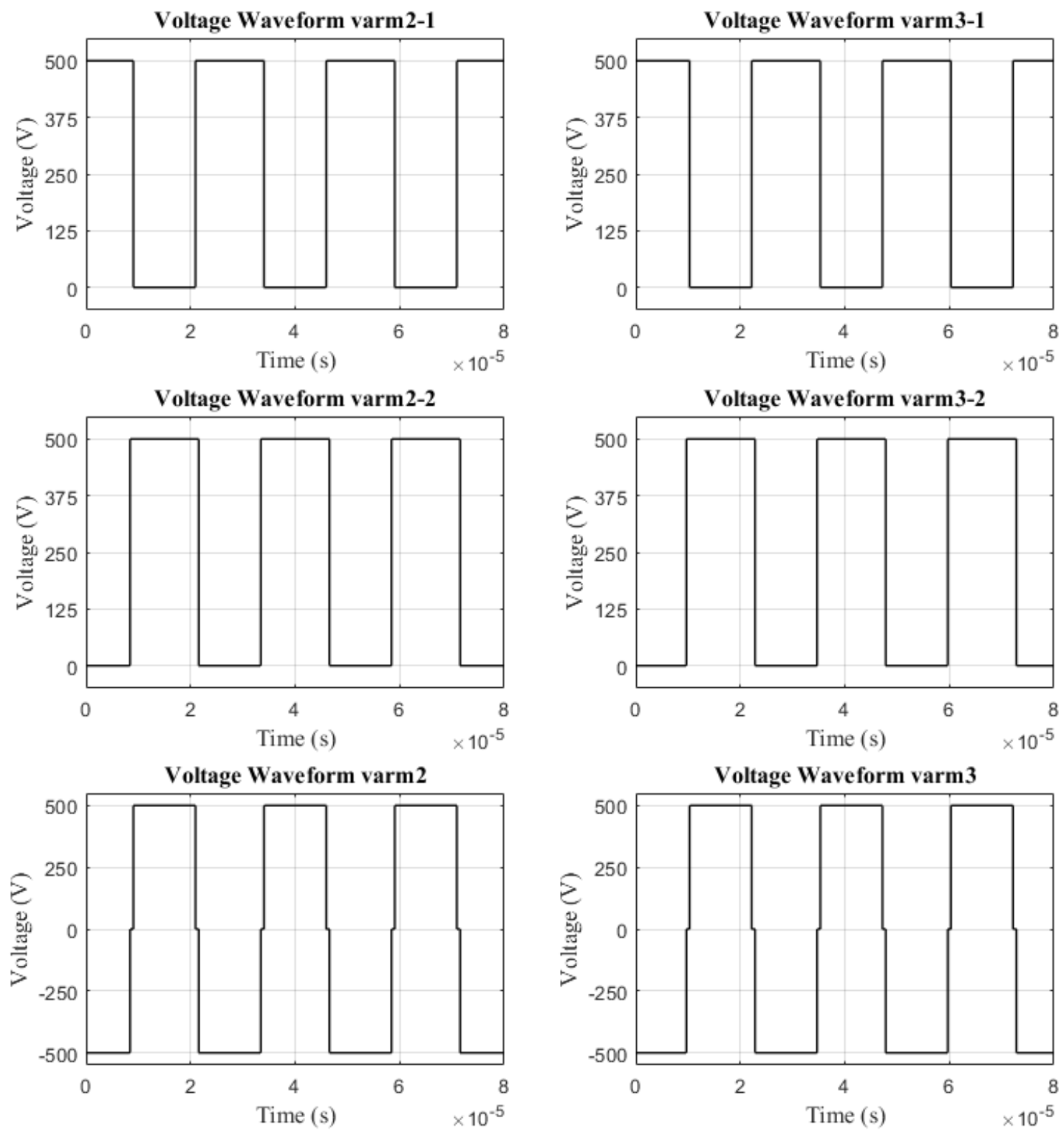

Figure 27: Individual arm voltages for each current-fed port and each port's voltage difference waveform 
Additional assumptions are made for the parameters not explicitly defined in the reference experiment. For instance, an $80 \%$ mutual coupling coefficient $M$ was selected in order to determine the mutual inductance $L_{M}$. Mutual coupling coefficients can have a wide range of values depending on the application and physical design of the inductor. $80 \%$ was selected because the effective inductance value $L_{d c}-L_{M}$ equaled the transformer leakage inductances $L_{2}$ and $L_{3}$. If a different value of $M$ is chosen, port voltages $v_{2}$ and $v_{3}$ will be affected because ports 2 and 3 contain mutual inductors. An analysis of converter performance with respect to varying values of $M$ is not included in this paper.

For simplification of the analysis and to keep the parameters similar to the reference experiment, the turns ratio of the transformer is kept at 1:1:1. Note that in order to maintain stable operation at an arbitrary current fed port $x$, the arm voltage is related to the DC voltage with the following relationship:

$$
V_{x D C}=2 D_{x} V_{a r m x} .
$$

This relationship exists to maintain the coupled inductor Volt-second balance. Deviating from this relationship will impose a DC current bias on the coupled inductors and could possibly lead to instability. In practice, this means the capacitors within the arm submodules will require cell voltage balancing to enforce a constant overall arm voltage. See Figure 28 and Figure 29 for an example of unstable current vs stable current in the high-side mutual inductor of port 2 due to Volt-second imbalance. 
Inductor Current i2dch1

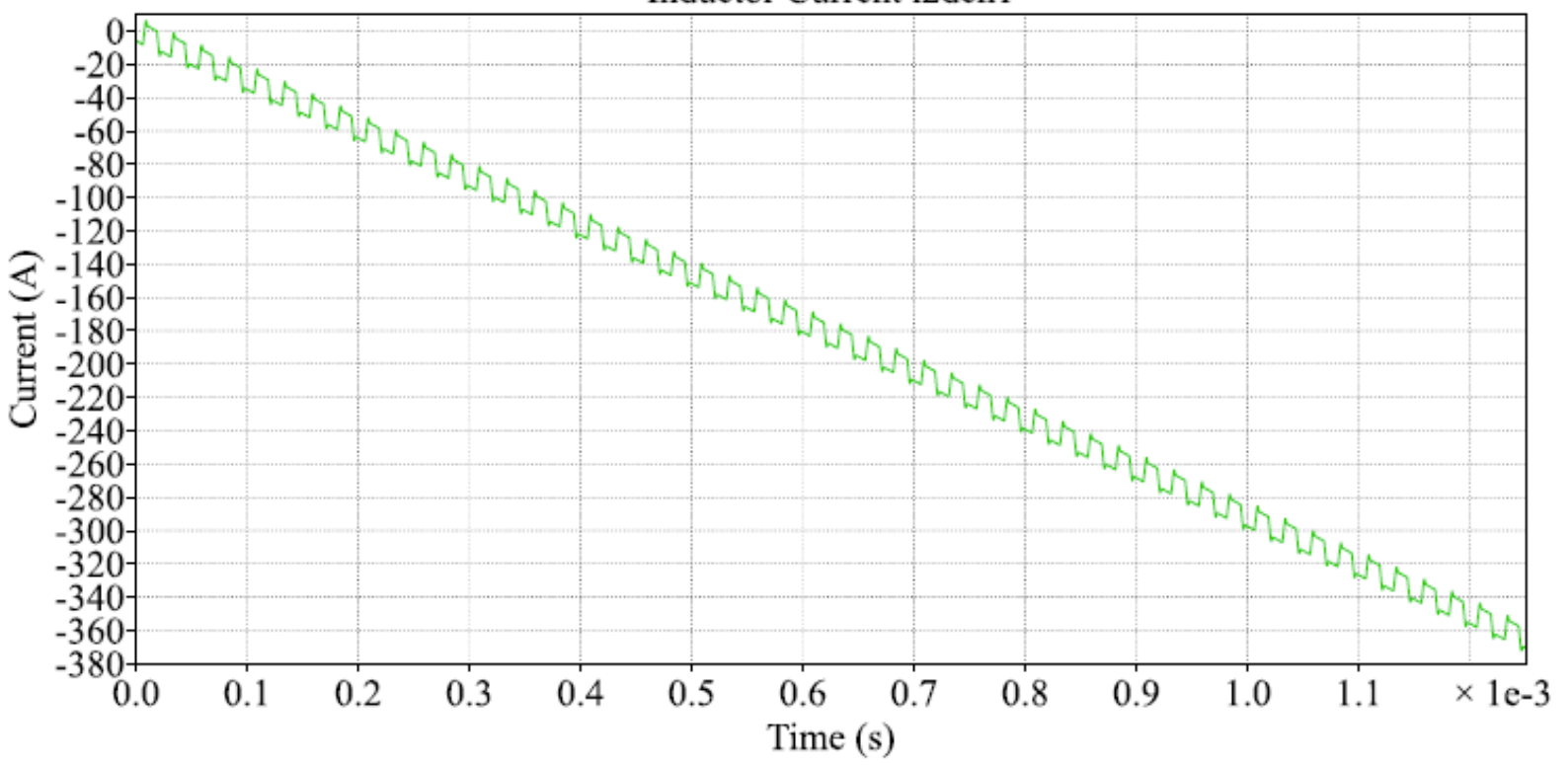

Figure 28: Unstable port 2 operation when $V_{2 D C} \neq 2 D_{2} V_{\text {arm2 }}$.

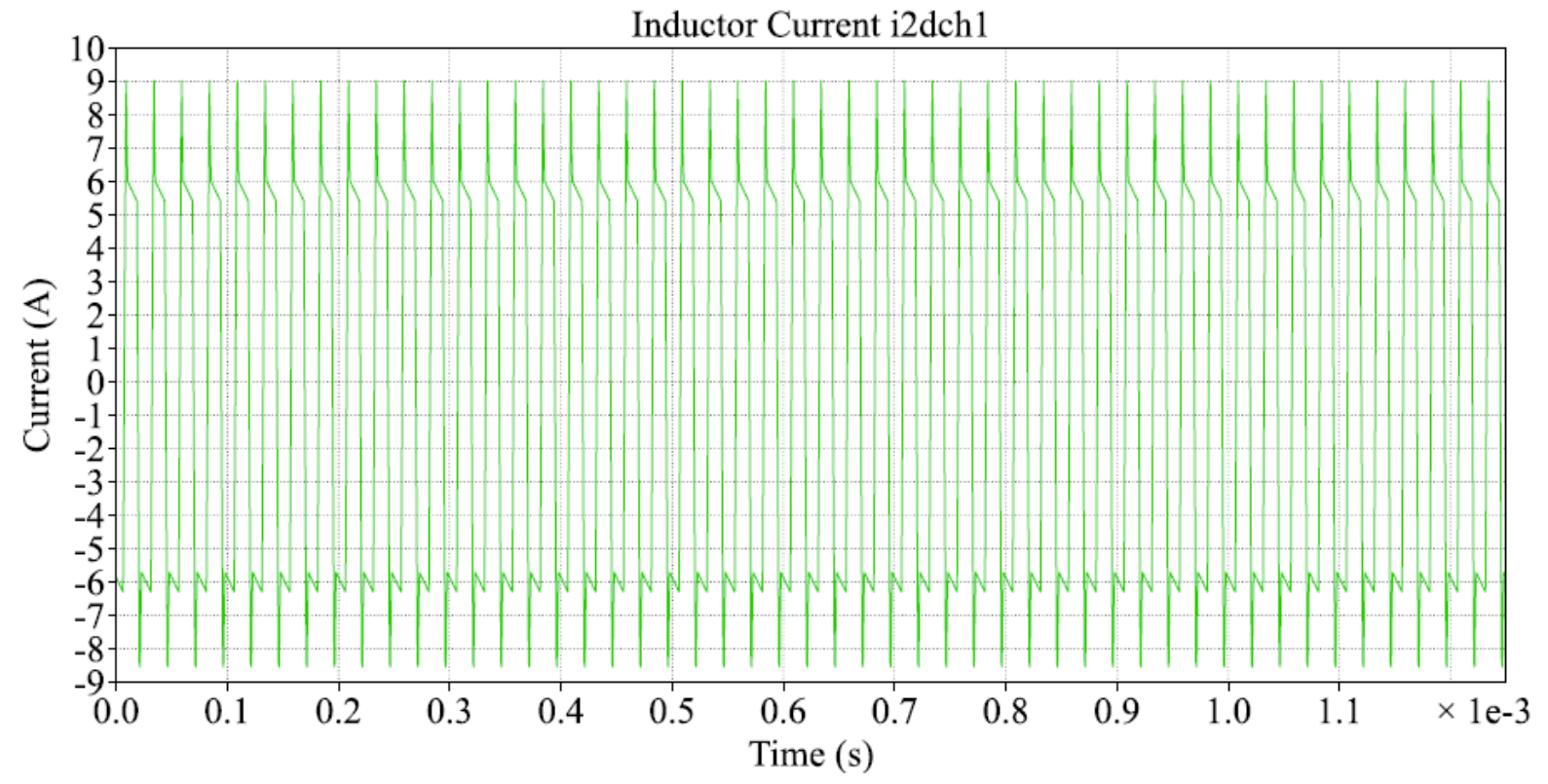

Figure 29: Stable port 2 operation when $V_{2 D C}=2 D_{2} V_{a r m 2}$ 

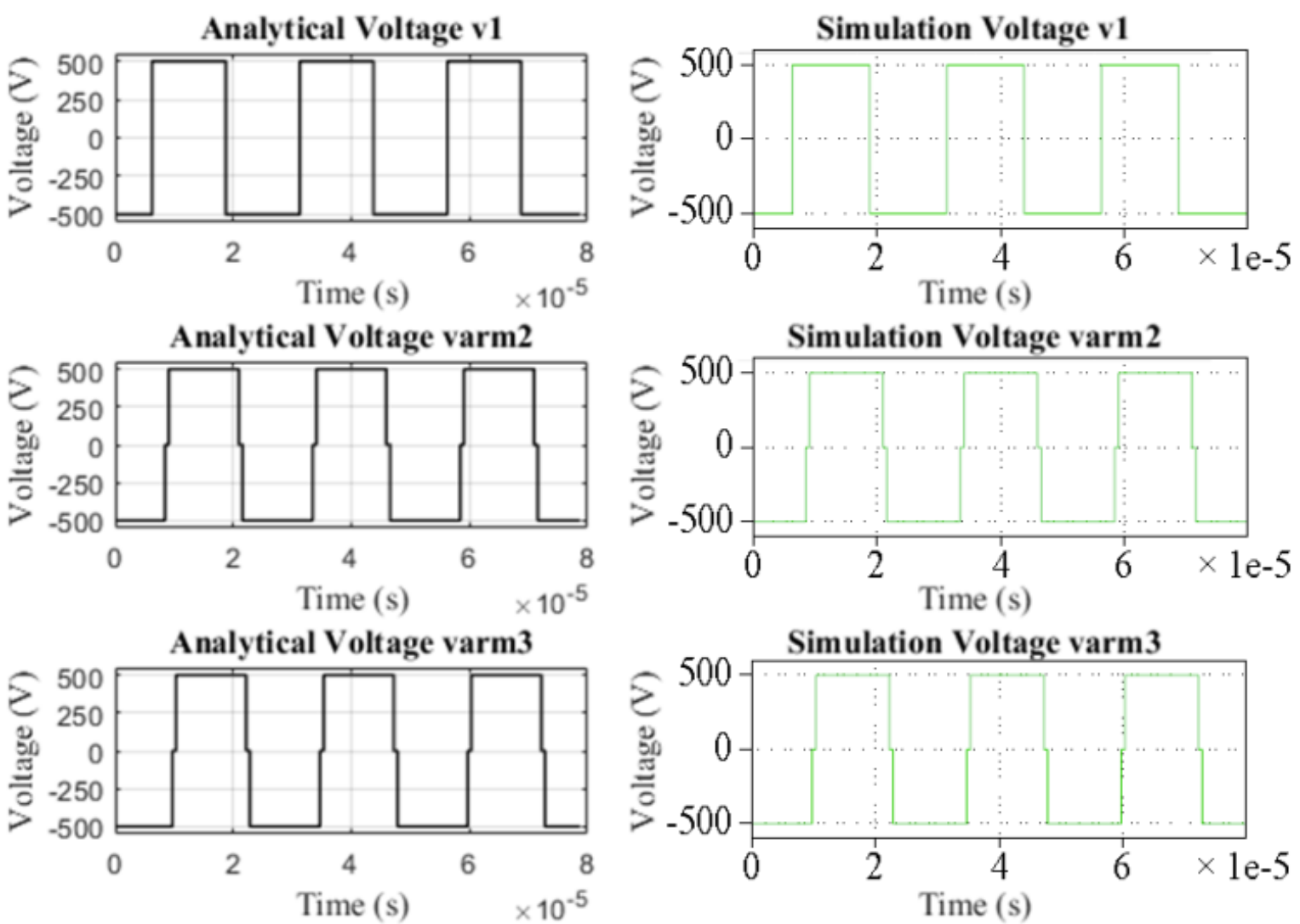

Analytical Voltage v2
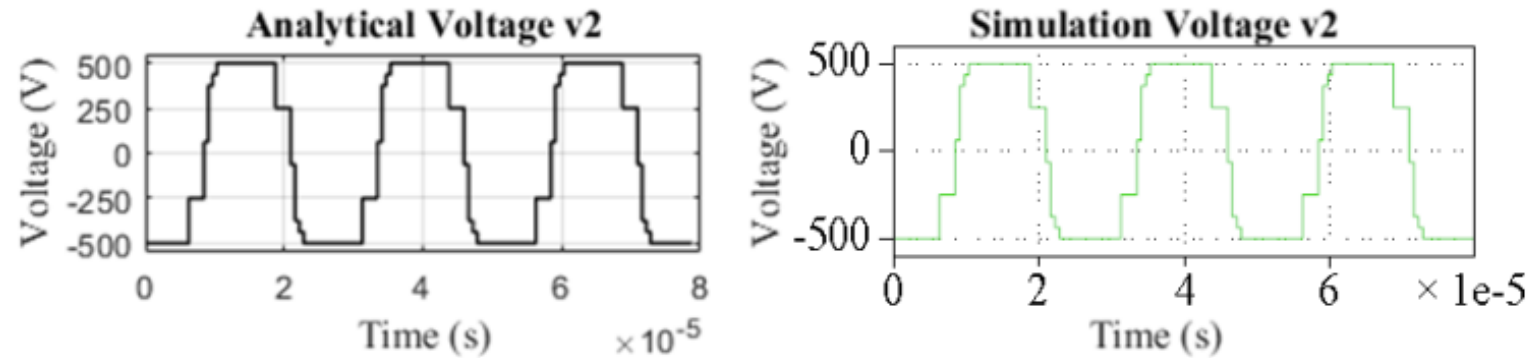

Analytical Voltage v3
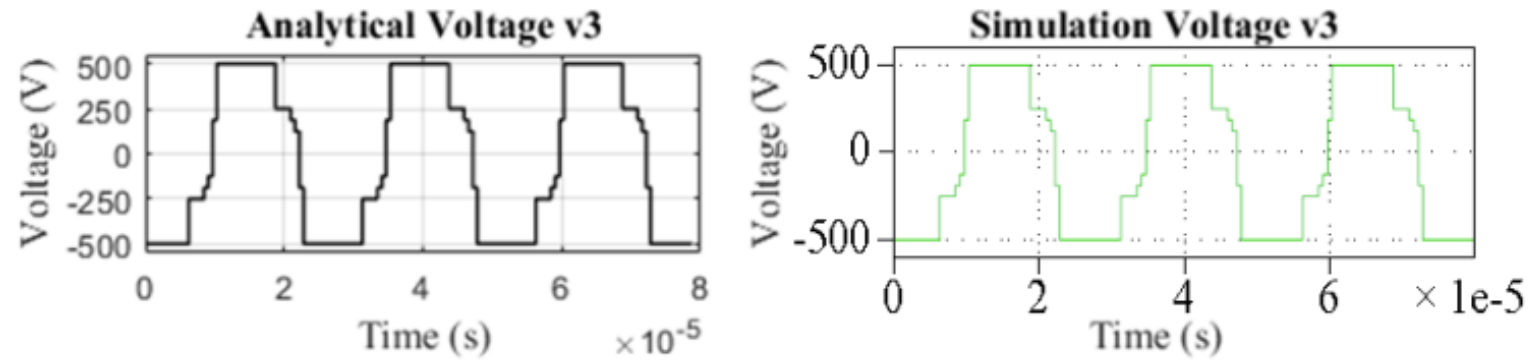

Figure 30: Analytical vs PLECS simulation waveforms for port voltages and switching waveforms 
The switching phase angle delays $\phi_{2}$ and $\phi_{3}$ for the secondary and tertiary ports, respectively, are selected to be different to conveniently observe the effects of switching at each port. As shown in Figure 30, a key feature of the converter voltages $v_{2}$ and $v_{3}$ is that the voltages deviate further from an ideal square wave as the phase angle delays $\phi_{x}$ increase. Therefore, the phase angle delays were kept at relatively small values $(0.1$ and 0.15$)$. The "notches" in voltages $v_{2}$ and $v_{3}$ are due to the switching behavior of each port. A design method to establish ideal square waveforms for $v_{2}$ and $v_{3}$ will be discussed later in Section 5.0. The simulation waveforms support the results from the mathematical analysis. In order to verify that the equations are accurate across various operating ranges, simulation results were compared to the analysis under different phase angle delays and duty cycles. A few example results of those simulations are included in an appendix for review if desired. 

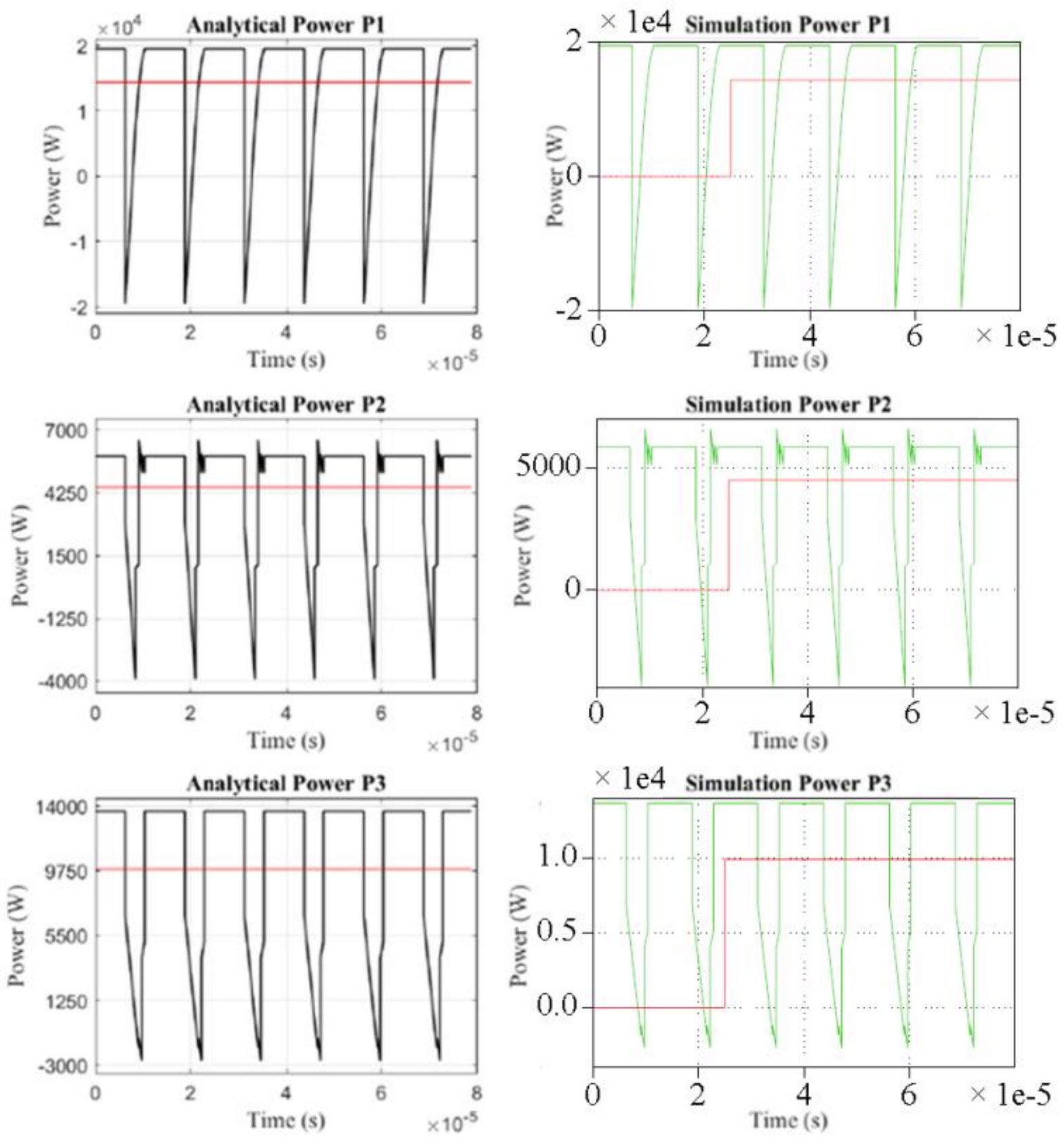

Figure 31: Analytical vs PLECS simulation waveforms for power flow at each port 
Figure 30 shows that the equations from the analyses accurately predict the behavior of the converter. It is clear that by using the selected parameters, the current-fed port voltages $v_{2}$ and $v_{3}$ cannot be assumed to be square waveforms when the transformer leakage inductance value is close in magnitude to the mutual inductance values. It is also clear that port voltages $v_{2}$ and $v_{3}$ are affected any time switching occurs at another port. Calculation of power flow through the converter is done by applying the formula in (32). The resulting power flow waveforms are shown in Figure 31 and confirmed with the power flow results from the simulation. 


\subsection{Discussions}

Looking at the comparison between analytical and simulation voltage waveforms in Figure 30 , it is clear that the port voltage equations accurately describe the performance of the converter. Similarly, the equations for power flow at each port are confirmed with the simulation results in Figure 31. The peak power values as well as average power (shown in red) are equivalent between the analysis and the simulation. Note that it takes one switching period for the simulation to calculate average power (half a period in this instance, due to symmetry) thus average power is defined as zero before a switching period elapses for the simulation.

A key result of these analyses is that the current-fed port voltages $v_{2}$ and $v_{3}$ deviate from an ideal square wave as the mutual inductance values $\left(L_{d c}-L_{M}\right)$ are increased to values similar in magnitude to the transformer leakage inductances $L_{2}$ and $L_{3}$. To explore this phenomenon further, the mutual inductance values $\left(L_{d c}-L_{M}\right)$ were varied between $1 \%$ and $200 \%$ of the transformer leakage inductance values $L_{2}$ and $L_{3}$. Figure 32 shows that the selection of inductor values significantly affects the port voltage waveforms and ultimately the performance of the converter. 

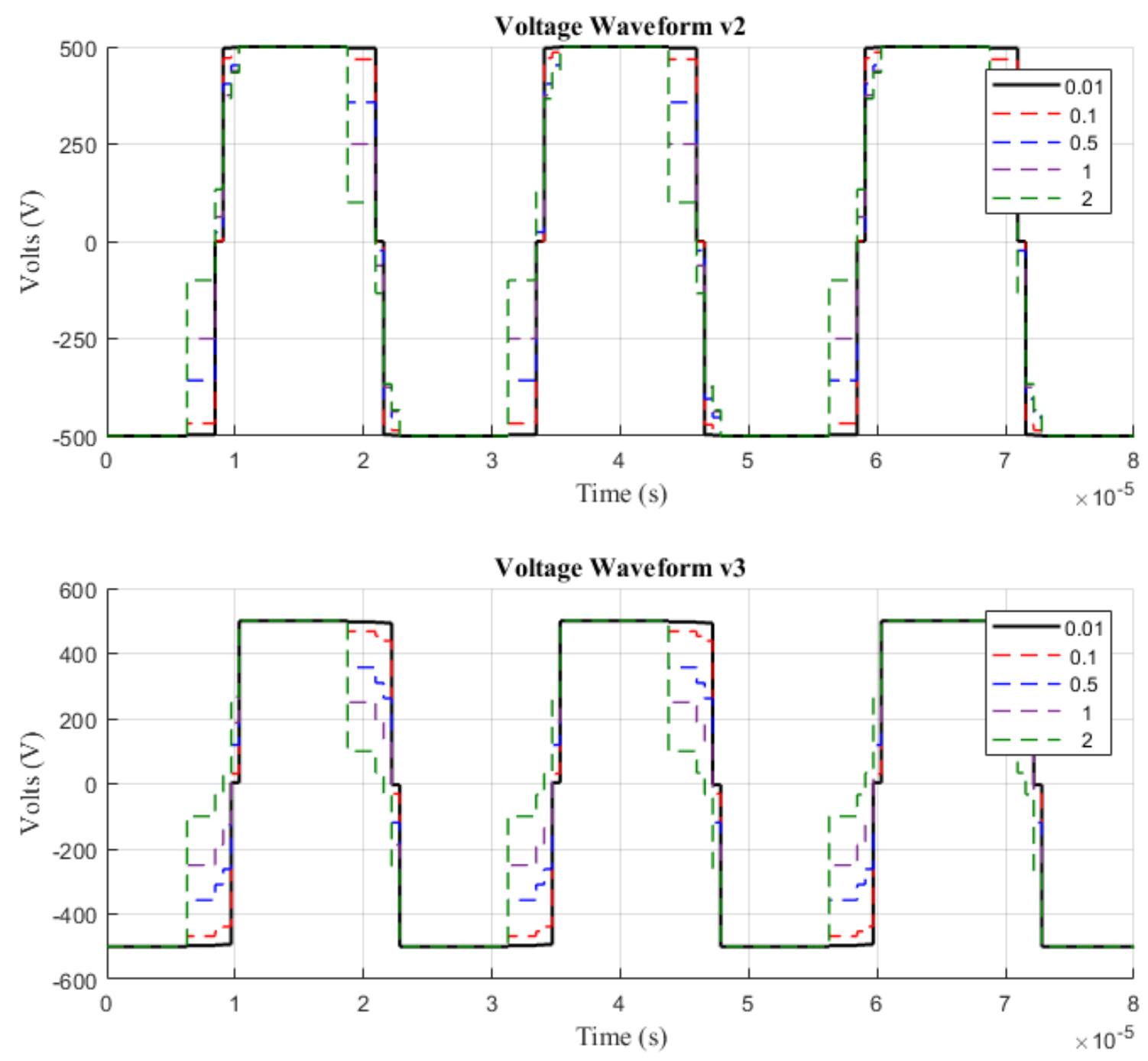

Figure 32: Current-fed port voltage waveforms $v_{2}$ and $v_{3}$ with inductance ratios $\left(L_{d c}-L_{M}\right) / L_{x}$ between $1 \%$ and $200 \%$ (results taken from PLECS simulation) 
When the mutual inductance values are $1 \%$ of the transformer leakage inductance values, the port voltage waveform is approximately a square wave (with zero states in accordance to the switching duty cycle). Due to the relatively short period of the zero states, each port voltage waveform can be approximated as an ideal square wave in order to compute power flow.

Therefore, when mutual inductance values are much lower than transformer leakage inductance values, the traditional power flow equations for voltage-fed multi-port converters as listed in [1] can be used. With the parameters listed in Table I, power flow at the current-fed ports was computed and compared to the expected power flow from the voltage-fed power flow equations in [1]. The results shown in Figure 33 demonstrate that as the mutual inductance $\left(L_{d c}-L_{M}\right)$ increases, the current-fed ports deliver less power than the "ideal power transfer" computed from the voltage-fed power flow equations.

A key finding from the results of Figure 33 is that traditional 3-port power flow control can be used if the mutual inductance is much less than the value of the transformer leakage inductance. However, as established in [7], the mutual inductance needs to be a significant value in order to provide fault ride-through operation. 

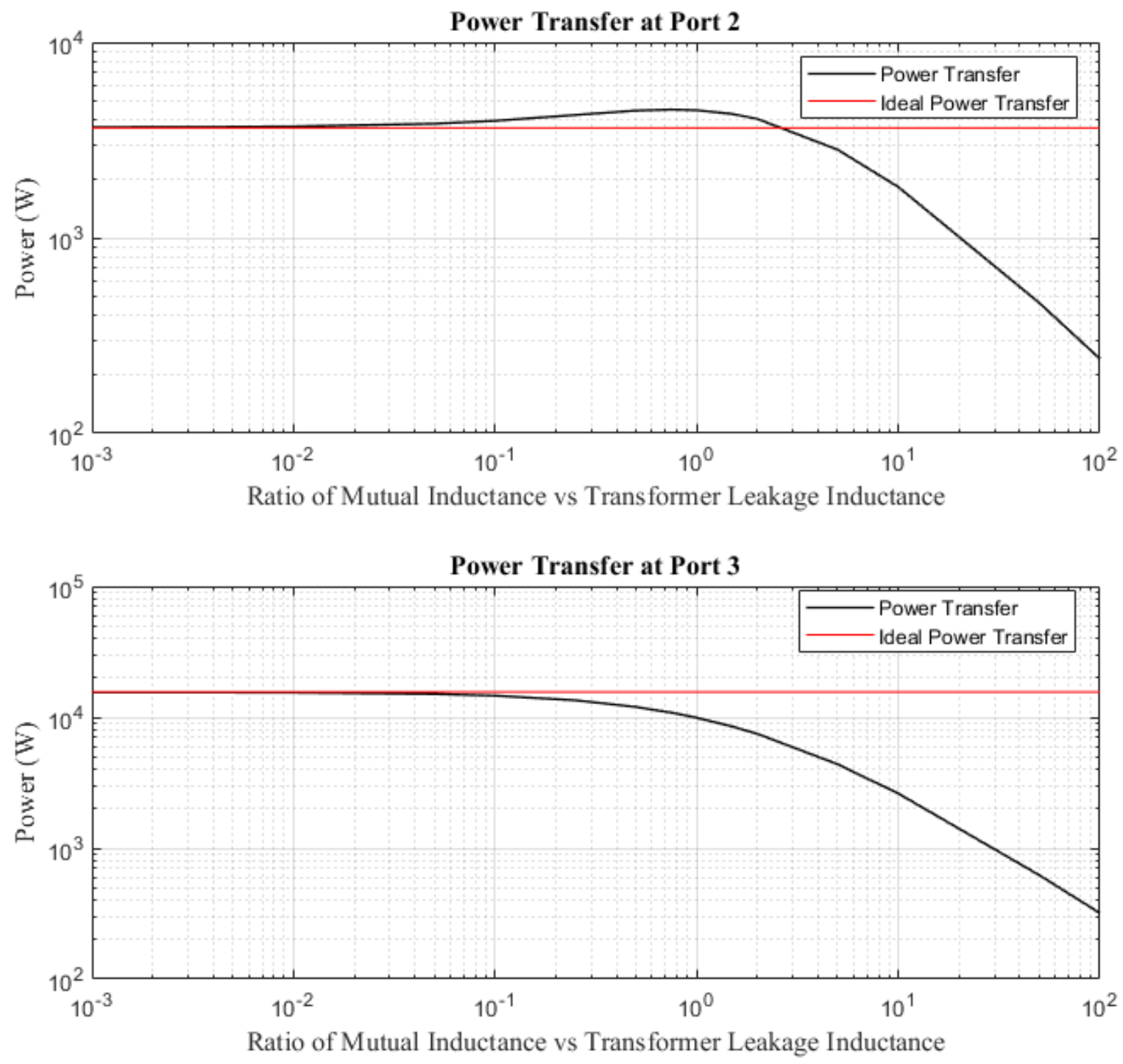

Figure 33: Power transfer at current-fed ports with respect to the inductance ratios $\left(L_{d c}-L_{M}\right) / L_{x}($ results taken from PLECS simulation) 


\subsection{Conclusions}

This analysis established characteristic equations for voltage, current, and power flow within a current-fed, multi-port converter. Waveforms were generated from the characteristic equations and confirmed with a PLECS simulation using circuit parameters from a reference experiment. Additionally, the validity of traditional power flow equations for a voltage-fed multiport converter were tested against the performance of the current-fed, multi-port DAB converter. The results confirm the accuracy of the derived equations. The results also imply that under certain conditions, a current-fed port's power flow can be controlled in the same manner as a voltage-fed port; however, some fault ride-though capability might be lost. 


\section{Appendix A Verification of Equations Under Various Circuit Parameters}

Shown below are the characteristic waveforms under different phase angle delays and duty cycles in order to confirm the accuracy of the derived equations. It is clear that the waveforms are equivalent for the analysis and for the simulation under each set of conditions. The method of plotting in MATLAB occasionally would have an error when drawing the line of the analytical voltage negative states, but that is a visual error and does not affect the voltage values at those particular times. It is clear from these plots how the relatively large mutual inductance value leads to voltage waveforms of $v_{2}$ and $v_{3}$ that are not ideal square waves. 

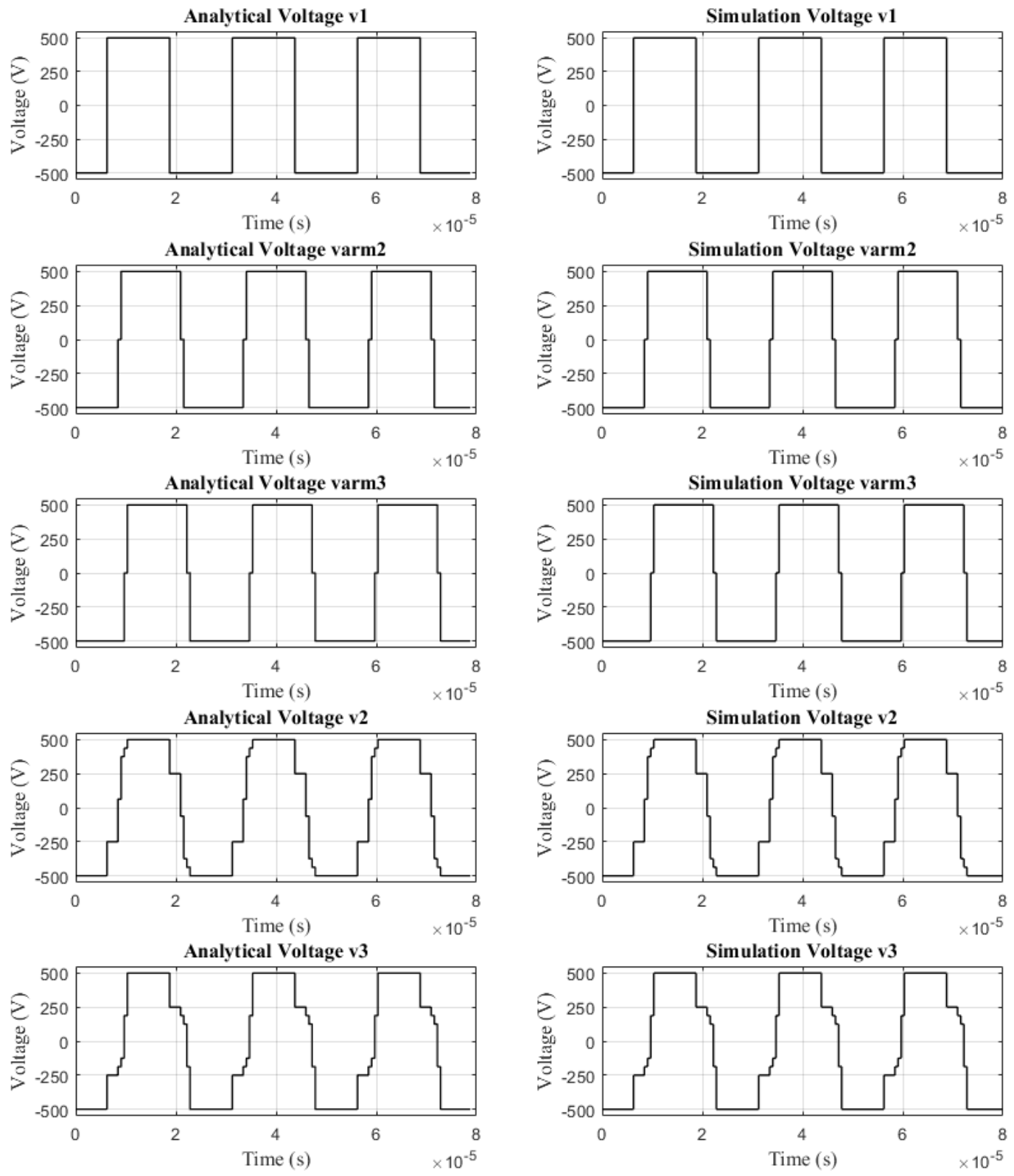

Figure 34: Analytical vs simulation waveforms, $\left[D_{1}, D_{2}, D_{3}\right]=[0.5,0.525,0.525]$ and $\left[\phi_{2}, \phi_{3}\right]=[0.1,0.15]$ 

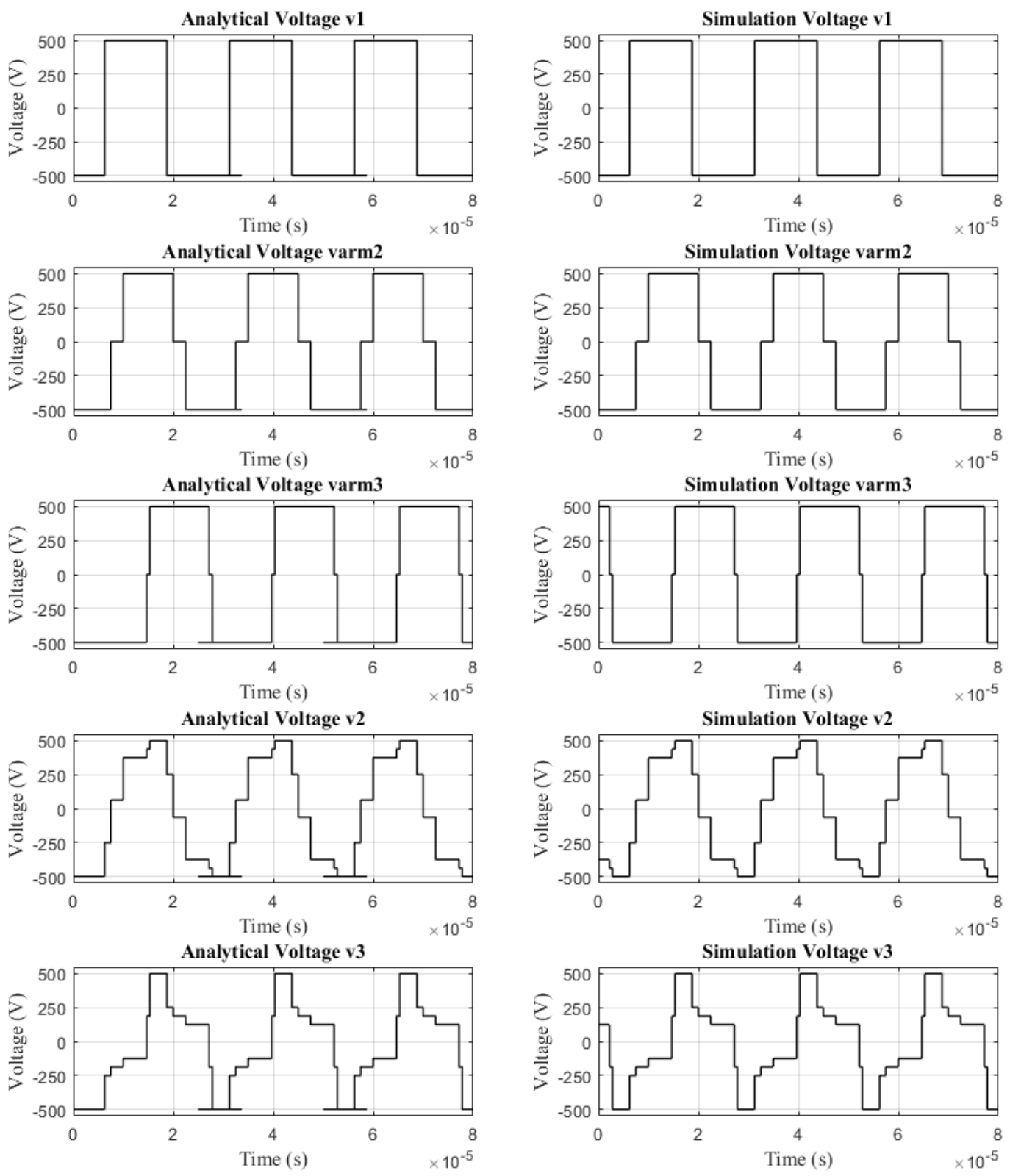

Figure 35: Analytical vs simulation waveforms, $\left[D_{1}, D_{2}, D_{3}\right]=[0.5,0.6,0.525]$ and $\left[\phi_{2}, \phi_{3}\right]=[0.1,0.35]$ 

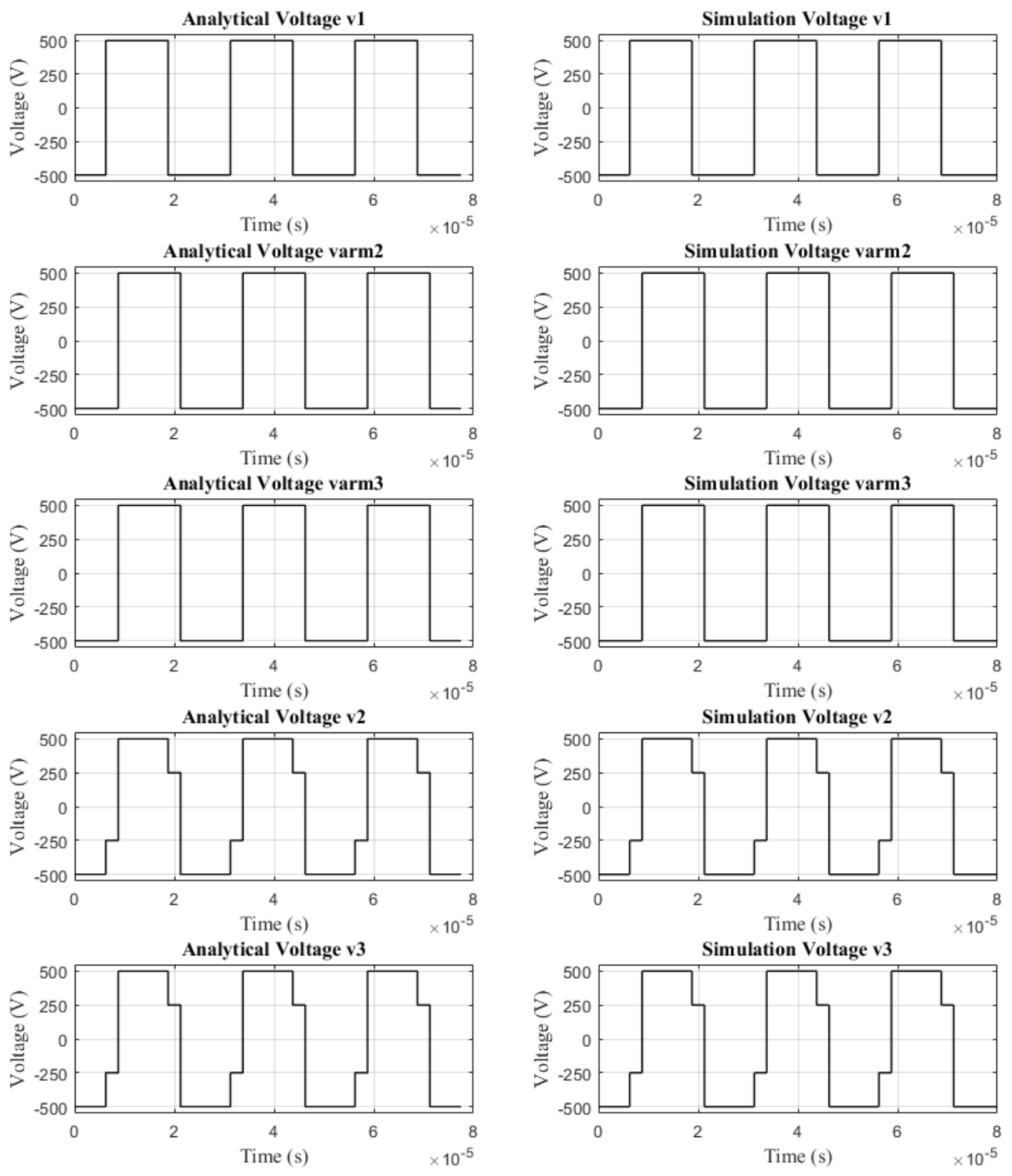

Figure 36: Analytical vs simulation waveforms, $\left[D_{1}, D_{2}, D_{3}\right]=[0.5,0.5,0.5]$ and $\left[\phi_{2}, \phi_{3}\right]=[0.1,0.1]$ 

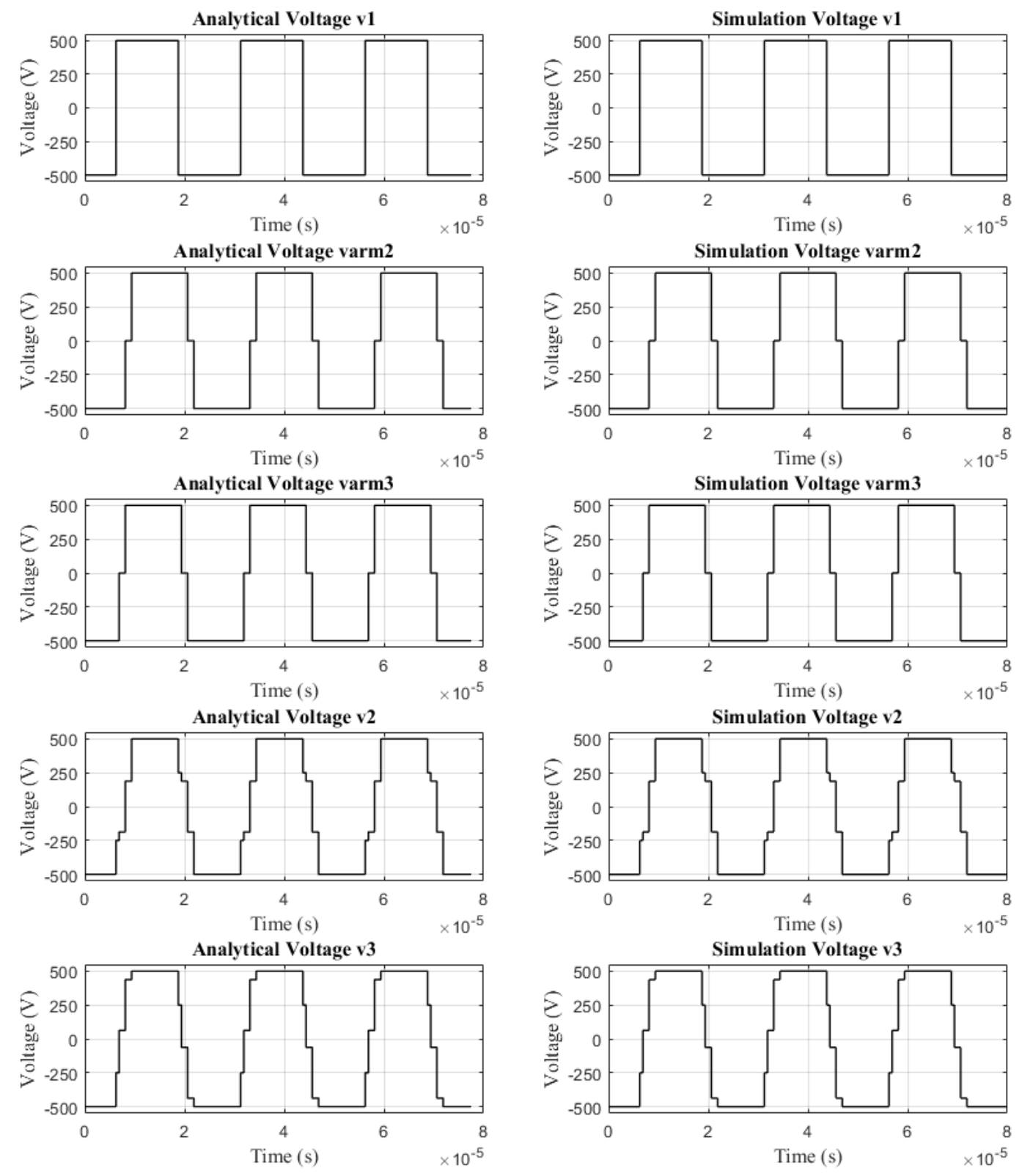

Figure 37: Analytical vs simulation waveforms, $\left[D_{1}, D_{2}, D_{3}\right]=[0.5,0.55,0.55]$ and $\left[\phi_{2}, \phi_{3}\right]=[0.1,0.05]$ 

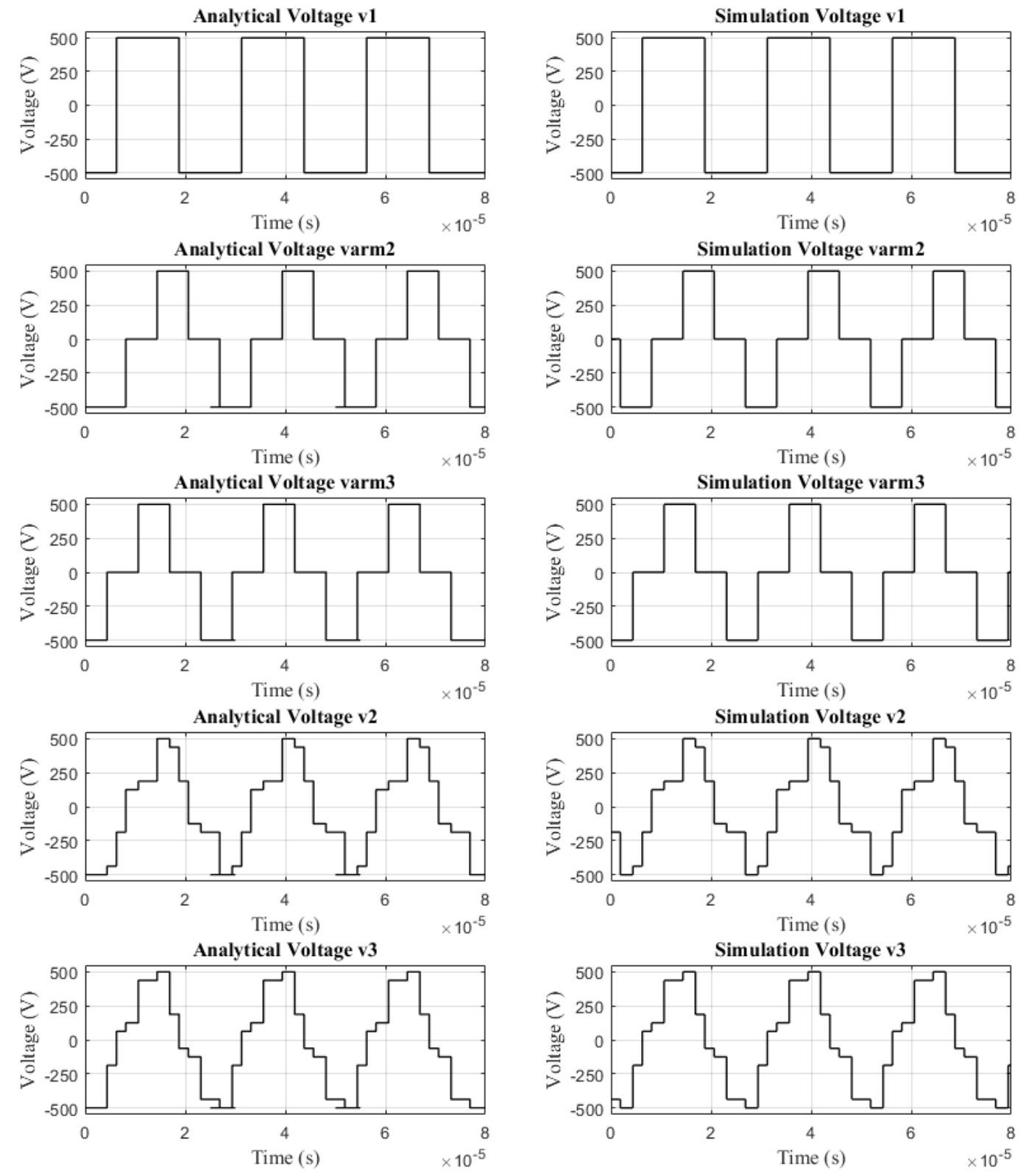

Figure 38: Analytical vs simulation waveforms, $\left[D_{1}, D_{2}, D_{3}\right]=[0.5,0.75,0.75]$ and $\left[\phi_{2}, \phi_{3}\right]=[0.2,0.05]$ 


\section{Bibliography}

[1] M. Michon, J. L. Duarte, M. Hendrix, and M. G. Simões, "A three-port bi-directional converter for hybrid fuel cell systems," PESC Rec. - IEEE Annu. Power Electron. Spec. Conf., vol. 6, pp. 4736-4742, 2004.

[2] H. Tao, A. Kotsopoulos, J. L. Duarte, and M. A. . Hendrix, "Family of multiport bidirectional DC-DC converters," IEE Proceedings-Electric Power Appl., vol. 150, no. 2, pp. 139-145, 2003.

[3] S. P. Engel, M. Stieneker, N. Soltau, S. Rabiee, H. Stagge, and R. W. De Doncker, "Comparison of the modular multilevel DC converter and the dual-active bridge converter for power conversion in HVDC and MVDC grids," IEEE Trans. Power Electron., vol. 30, no. 1, pp. 124-137, 2015.

[4] F. Mura and R. W. De Doncker, "Design aspects of a medium-voltage direct current (MVDC) grid for a university campus," 8th Int. Conf. Power Electron. - ECCE Asia "Green World with Power Electron. ICPE 2011-ECCE Asia, no. Mvdc, pp. 2359-2366, 2011.

[5] A. Q. Huang and R. Burgos, "Review of Solid-State Transformer Technologies and Their Application in Power Distribution Systems," IEEE J. Emerg. Sel. Top. Power Electron., vol. 1, no. 3, pp. 186-198, 2013.

[6] Y. Shi, R. Li, Y. Xue, and H. Li, "Optimized Operation of Current-Fed Dual Active Bridge DC-DC Converter for PV Applications," IEEE Trans. Ind. Electron., vol. 62, no. 11, pp. 6986-6995, 2015.

[7] Y. Shi, R. Mo, H. Li, and Z. Pan, "A novel ISOP current-Fed modular dual-Active-Bridge (CF- MDAB) DC- DC converter with DC fault ride-Through capability for MVDC application," 2017 IEEE Energy Convers. Congr. Expo. ECCE 2017, vol. 2017-Janua, pp. 4525-4530, 2017.

[8] Y. Shi, L. Liu, H. Li, and Y. Xue, "A single-phase grid-connected PV converter with minimal DC-link capacitor and low-frequency ripple-free maximum power point tracking," 2013 IEEE Energy Convers. Congr. Expo. ECCE 2013, pp. 2385-2390, 2013.

[9] Z. Wang and H. Li, "An integrated three-port bidirectional DC-DC converter for PV application on a DC distribution system," IEEE Trans. Power Electron., vol. 28, no. 10, pp. 4612-4624, 2013.

[10] A. K. Rathore and U. R. Prasanna, "Comparison of soft-switching voltage-fed and currentfed bi-directional isolated Dc/Dc converters for fuel cell vehicles," IEEE Int. Symp. Ind. Electron., pp. 252-257, 2012. 
[11] R. W. A. A. De Doncker, D. M. Divan, and M. H. Kheraluwala, "A Three-phase SoftSwitched High-Power-Density dc /dc Converter for High-Power Applications," vol. 27, no. 1, pp. 63-73, 1991.

[12] B. Zhao, Q. Song, W. Liu, and Y. Sun, "Overview of dual-active-bridge isolated bidirectional DC-DC converter for high-frequency-link power-conversion system," IEEE Trans. Power Electron., vol. 29, no. 8, pp. 4091-4106, 2014.

[13] H. Tao, A. Kotsopoulos, J. L. Duarte, and M. A. M. Hendrix, "Transformer-coupled multiport ZVS bidirectional DC-DC converter with wide input range," IEEE Trans. Power Electron., vol. 23, no. 2, pp. 771-781, 2008.

[14] P. Xuewei and A. K. Rathore, "Comparison of bi-directional voltage-fed and current-fed dual active bridge isolated dc/dc converters low voltage high current applications," IEEE Int. Symp. Ind. Electron., pp. 2566-2571, 2014.

[15] Y. Shi and H. Li, "Isolated Modular Multilevel DC-DC Converter With DC Fault Current Control Capability Based on Current-Fed Dual Active Bridge for MVDC Application," IEEE Trans. Power Electron., vol. 33, no. 3, pp. 2145-2161, 2018. 